\title{
FEM-based prediction of workpiece transient temperature distribution and deformations during milling
}

\author{
Jitender K. Rai • Paul Xirouchakis
}

Received: 12 March 2008 / Accepted: 10 June 2008/Published online: 31 July 2008

(C) Springer-Verlag London Limited 2008
Abstract In high-speed dry milling of thin-walled parts, the cutter-workpiece temperature rises asymptotically with cutting speed, causing excessive cutter tooth wear and workpiece thermal expansion, which in turn re- duces the cutter life and produces dimensional and geo- metrical variabilities in the machined part. Therefore, a basic understanding of the thermal aspect of machining and the effecting parameters is essential for achieving better part quality with improved productivity. This paper presents a transient milling simulation model to assist manufacturing engineers in gaining in-depth un- derstanding of the thermomechanical aspects of ma- chining and their influence on resulted part quality. Based on the finite-element method approach, the model can predict transient temperature distributions and resulted elastic-plastic deformations induced dur- ing the milling of $2.5 \mathrm{D}$ prismatic parts comprising fea- tures like slots, steps, pockets, etc. The advantages of the proposed model over previous works are that it (1) performs feature-based machining simulation consid- ering transient thermomechanical loading conditions; (2) allows modeling the effects of coolant on convec- tive heat transfer rate; and (3) considers the nonlinear behavior of the workpiece due to its changing geome- try, inelastic material properties, and flexible fixture- workpiece contacts. The prediction accuracy of the model was validated with experimental results obtained
J. K. Rai · P. Xirouchakis $(\varangle)$
Institute of Production and Robotics, LICP, EPFL,
1015 Lausanne, Switzerland
e-mail: paul.xirouchakis@epfl.ch
J. K. Rai
e-mail: jitenderkumar.rai@epfl.ch
during the course of the research work. A good agree- ment between the numerical and experimental results was found for different test cases with varying part geometries and machining conditions.
Keywords Milling • Finite-element methods •
Deformations $\cdot$ Cutting temperature $\cdot$ Cutting forces

\section{Nomenclature}
$D \quad$ Cutter diameter $(\mathrm{mm})$
$z \quad$ Number of flutes
$\beta \quad$ Helix angle (degrees)
$\alpha \quad$ Rake angle (degrees)
$h_{m} \quad$ Undeformed chip thickness (mm)
$V \quad$ Cutting speed $(\mathrm{m} / \mathrm{s})$
$V_{f} \quad$ Feed speed $(\mathrm{m} / \mathrm{s})$
$a_{p} \quad$ Axial depth of cut (mm)
$a_{e} \quad$ Radial depth of cut (mm)
$n \quad$ Spindle speed (rps)
$f_{t} \quad$ Feed-rate per tooth $(\mathrm{mm} /$ tooth $)$
$K_{c} \quad$ Specific cutting pressure $\left(\mathrm{N} / \mathrm{mm}^{2}\right)$
$U_{w} \quad$ Heat dissipated into the workpiece (W)
$\rho \quad$ Workpiece material density $\left(\mathrm{kg} / \mathrm{m}^{3}\right)$
$K \quad$ Workpiece thermal conductivity $(\mathrm{W} / \mathrm{m}-\mathrm{K})$
$C_{p} \quad$ Workpiece specific heat $(\mathrm{J} / \mathrm{kg}-\mathrm{K})$
$T_{f} \quad$ Time to cover a feed-step (s)
$F_{\text {sub }} \quad$ Number of feed sub-steps
$F_{x} \quad$ Cutting force along feed direction (N)
$F_{z} \quad$ Cutting force along radial direction (N)
$F_{y} \quad$ Cutting force along axial direction (N)
$\mathrm{Vol}_{\text {mat }}$ Volume of material removed per feed-step $\left(\mathrm{m}^{3}\right)$
$T_{c} \quad$ Cutter contact duration (s)
$T_{\mathrm{nc}} \quad$ Cutter noncontact duration (s) 


$\begin{array}{ll}T & \text { Torque applied on a clamping bolt }(\mathrm{N}-\mathrm{mm}) \\ D_{b} & \text { Clamping bolt diameter }(\mathrm{mm}) \\ F_{\text {clamp }} & \text { Clamping load }(\mathrm{N}) \\ \text { CTE } & \text { Coefficient of thermal expansion }(\mathrm{m} / \mathrm{m}-\mathrm{K}) \\ E & \text { Young modulus }\left(\mathrm{N} / \mathrm{mm}^{2}\right) \\ E_{T} & \text { Tangent modulus }\left(\mathrm{N} / \mathrm{mm}^{2}\right) \\ Y & \text { Yield strength }\left(\mathrm{N} / \mathrm{mm}^{2}\right) \\ \mu & \text { Poisson ratio }\end{array}$

\section{Introduction}

Today, the high-speed machining process has found wide acceptance among the manufacturing community, especially in the aircraft and automotive sectors, because of its enhanced productivity. It has been successfully applied for manufacturing large-size thin-walled structural parts of light-weight aluminium alloy. Despite the wide application of this advanced technology, it still faces a severe problem of inducing very high cutting temperatures causing excessive thermal expansion of the workpiece specifically under dry machining conditions. The cutting parameters, namely, cutting speed and feed rate, have the greatest influence on the cutting temperature. Since cutting forces generally do not vary strongly with cutting speed, increasing the cutting speed increases the energy dissipation rate through plastic deformation and, thus, the rate of heat generation in the cutting zone [22]. If the thermal conductivity $(K)$ and heat capacity $\left(\rho C_{p}\right)$ of the work material is higher, then the generated heat is more readily conducted into the workpiece, causing thermal expansions, which can produce severe part irregularities. Dimensional and form errors due to this source can be minimized by designing an appropriate machining operation sequence such that part features with critical tolerances will be machined first to avoid heating the part when cutting noncritical features [22]. Therefore, for making an appropriate choice of the cutting parameters and the operation sequence, in-depth understanding of the heat transfer phenomenon during machining is necessary.

In the recent past, various techniques have been developed for studying the thermal aspects of machining and are broadly classified into two, namely, (1) the experimental approach and (2) the numerical approach. With the recent developments in machining automation, various cutting temperature measurement techniques, including tool-work thermocouple, embedded thermocouple, and infrared pyrometer, emerged. Literature reveals that the aforesaid experimental techniques have been widely applied in the turning process $[10-13,16,22]$ due to its simplicity, whereas little work has been done in the milling process due

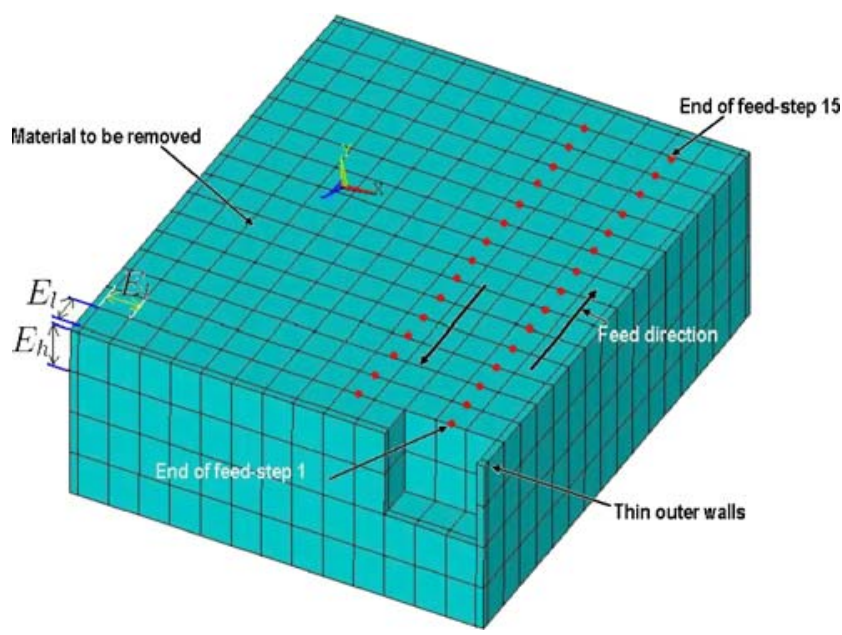

Fig. 1 Adaptively meshed raw stock FEM model showing volume of material removed at the end of feed-step one

to the difficulties that arise from the rotation of the cutter and the confined work space. Since it is also tedious to calculate directly the milling temperatures at the tool-work interface based on the plastic work of the chip formation as reported in [8], the inverse heat transfer method was employed in the works of Lin [8], Ming et al. [12], and Shen [21] for estimating the transient tool-face temperature and heat dissipation in the workpiece during a slot milling process using the measured workpiece surface temperature. Recently, various finite-element method (FEM) and finitedifference method (FDM) based numerical models were also proposed for the determination of the temperature distribution in the workpiece and the cutting tool [5, 15]. Lazoglu and Altintas [5] proposed a FDMbased oblique cutting model for the prediction of tool and chip temperature fields in continuous and intermittent cutting operations. In the recent work of Fang and Zeng [3] FEM was used in the development of a 3D model of the oblique cutting process for the prediction of temperature distribution in the workpiece, tool and chip. Most of these works mainly dealt with single-point oblique cutting operations, with a particular emphasis on the prediction of tool-chip interface temperature in the $\mathrm{CNC}$ turning process. Machining-induced temperature distribution in the workpiece was estimated for a simple single pass slot milling operations in

Table 1 Aluminium alloy (Al-7075) thermomechanical properties [20]

\begin{tabular}{lrlllc}
\hline$K$ & 130 & $C_{p}$ & 960 & $\rho$ & 2,810 \\
$E$ & 71,700 & $E_{T}$ & 900 & $Y$ & 503 \\
$K_{c}$ & 600 & CTE & $25.4 \times 10^{-6}$ & $\mu$ & 0.33 \\
\hline
\end{tabular}




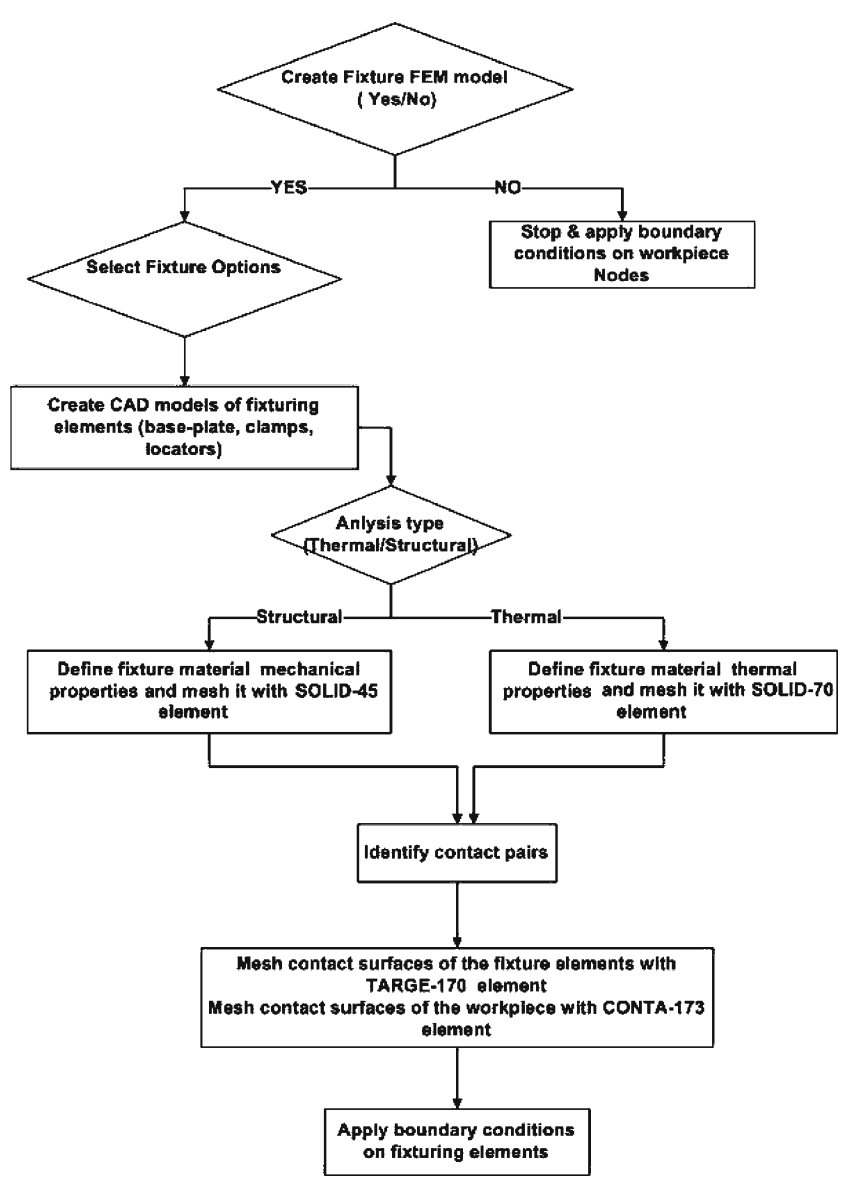

Fig. 2 Flowchart of the developed FEM-based fixture design module

only a few reported works $[8,12,21]$. However, these studies ignore the structural analysis of the machining process for predicting part deformations under coupled thermomechanical loading conditions.

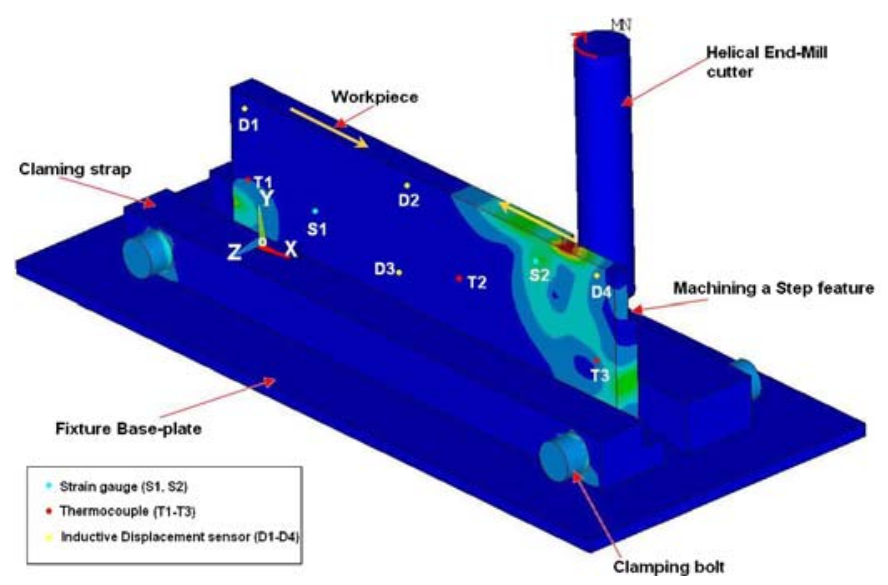

(a)
Despite a significant amount of published research work and developments in this area, there is still a lack of a comprehensive milling simulation model which, by taking into account the effects of the overall milling process parameters, namely, the operation sequence, the tool-path, the fixture layout, and the cutting variables (cutting speed, feed rate, and depth of cuts), simulates the thermomechanical aspects of machining. Increased attention is therefore being focused on the development of a computationally efficient milling process model, well capable to perform thermomechanical analysis of the metal cutting process in a 3Dvirtual machining environment and realistically predict the resulted part quality.

\section{Considerations}

The following considerations were made in the development of the FEM based milling simulation module:

- Temperature-independent material properties are assigned to the fixture-workpiece FEM model.

- The elastic-plastic FEM model of the workpiece and the fixture elements are created using the $b i$ linear isotropic hardening option available in the ANSYS program [1].

- Workpiece vibrations and cutting tooth wear that might occur during machining have been excluded for simplicity.

- Fixture-workpiece surface-surface flexible contact pairs can be created using the ANSYS contact modeling functionalities.

- The initial gap and penetration between the contact pair is assumed to be zero.

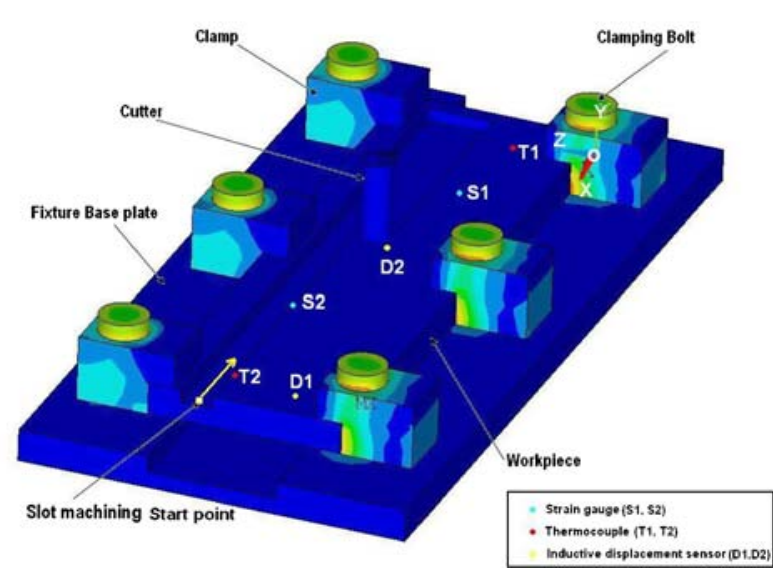

(b)

Fig. 3 Developed fixture configurations and measuring sensor locations. a Fixturing using strap clamps. b Fixturing using wedge clamps 
- Back and forth tool path strategies are only considered.

- Transient loading conditions are applied along the cutter trajectories.

\section{FEM-based milling simulation model}

In this work, for analyzing the phenomenon of heat dissipation into the workpiece and its influence on part deformation, a 3D model of the transient coupled field (thermomechanical) milling process was developed on top of a commercial FEM program called ANSYS [1]. The developed system allows users (1) to create

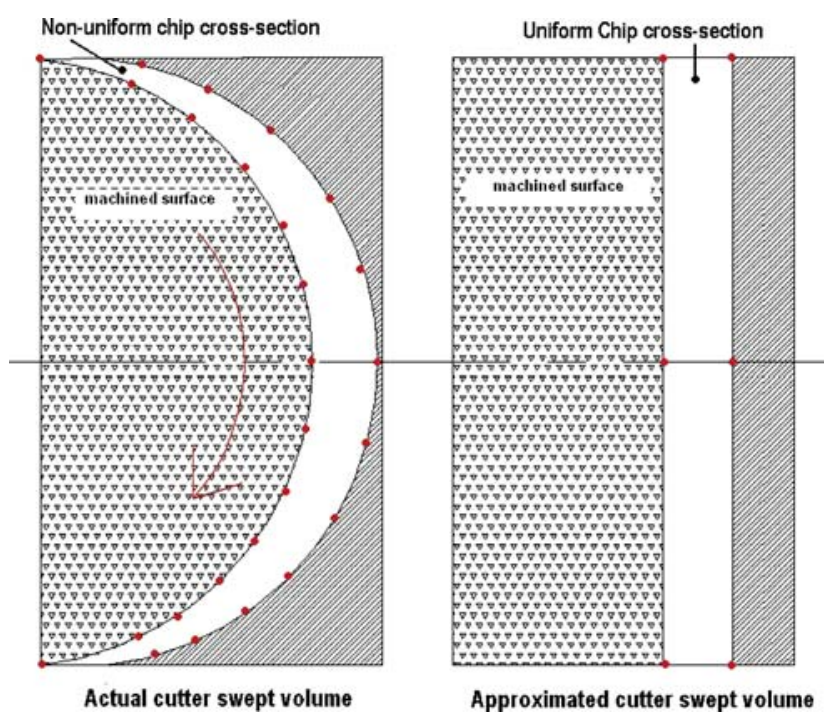

(a)

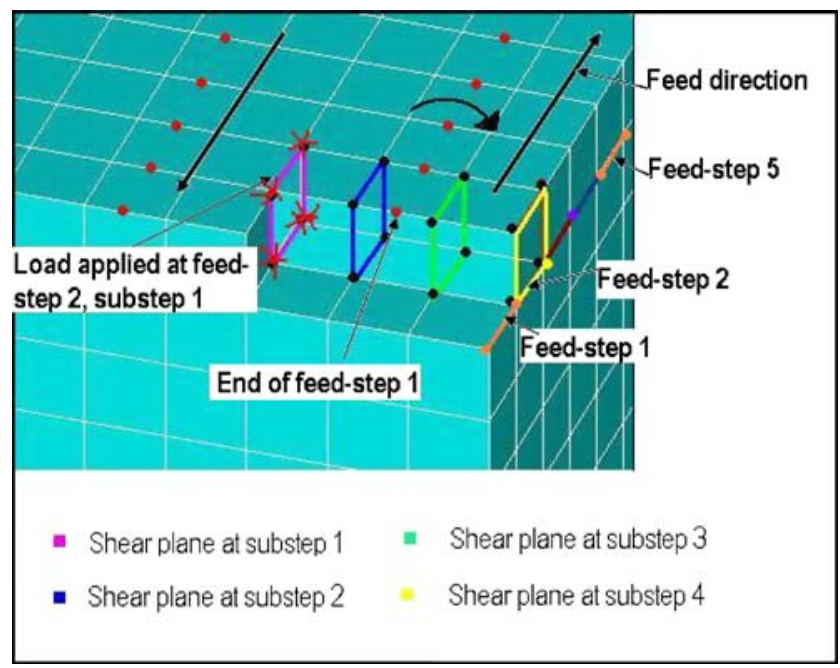

(b)

Fig. 4 Strategy to apply loads in the approximated cutting shear plane area. a Cutter swept volume during one feed step (radial feed from left to right). b Feed-step and shear plane description
3D FEM models of the fixture-workpiece configurations, (2) to apply appropriate machining boundary conditions (like coolant effects, degree-of-freedom constraints on fixturing elements, transient machining loads, etc.), and (3) to perform transient thermal analysis followed by structural analysis where the transient temperature distribution profiles (obtained in the thermal analysis) are applied along with the cutting forces to predict part deflections and elastic-plastic deformations during the machining process. Important steps involved in performing the milling process transient coupled field analysis are as follows:

Step 1 Construct finite-element model of the workpiece

First, the FEM model of the workpiece is created sequentially to perform the sequential thermomechanical coupled field analysis with the eight nodes thermal SOLID-70 and structural SOLID-45 brick elements using a uniform element size (i.e., $E_{l} \times E_{l} \times E_{h}$ as shown in Fig. 1) for parts having wall thickness greater than $3 \mathrm{~mm}$; otherwise, the adaptive mesh approach was used for reducing the computational time. The adaptive mesh was generated by first meshing the final part geometry with an element size equal to the wall thickness and then the workpiece volume to be removed during the transient machining simulation was meshed using coarser elements as shown in Fig. 1. The selected elements 3D transient conduction-convection modelling capabilities, compatibility for coupled field analysis, provision to import initial stresses, and death and birth features allow more realistic modeling of the material removal process. Workpiece material thermal and mechanical properties used in the present work are listed in Table 1.

Step 2 Construct finite-element model of the fixture elements

The working principle of the developed FEM-based fixture design module is demonstrated in Fig. 2. It allow users to either create a fixture-workpiece contact model or simply apply fixturing by constraining workpiece surface nodes. Using the first option, one can achieve better accuracy over the latter due to its flexible boundary conditions but has to pay more in terms of computational time (approximately 10 times for the considered test cases) comparing to the one with rigid boundary conditions. In this work, fixtureworkpiece surface-surface contact pairs are modeled using the ANSYS TARGE 170 and CONTA 173 fournode contact elements. As contact problems are highly nonlinear, consideration of complex fixture element geometry may result in excessive computational cost 
Fig. 5 CAD model of a test part (numbering $1-8$ corresponds to machining feature IDs)

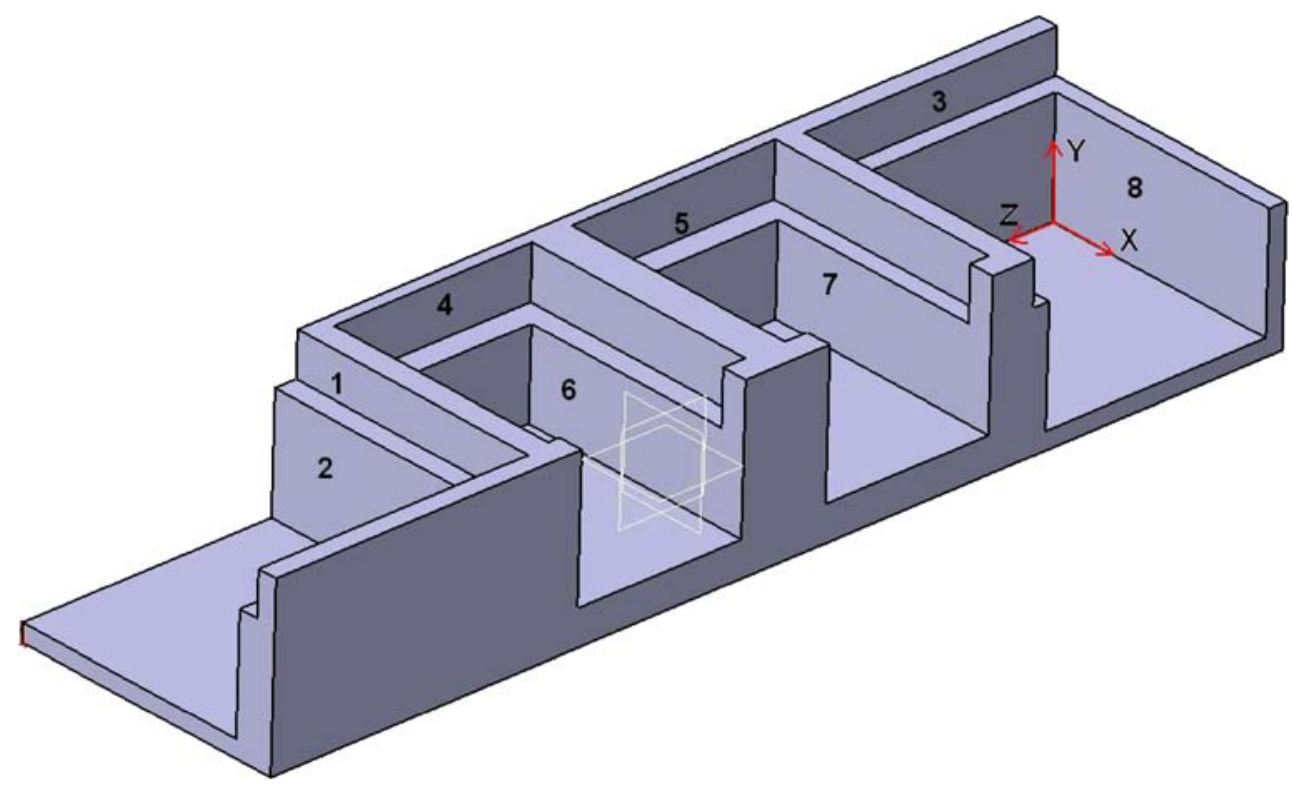

or even cause convergence problems; therefore, to enhance the performance and avoid convergence failure, strap clamps, wedge clamps, and C-clamps [14] with screw fasteners were considered. A fixture design module with a user interface has been developed and integrated within the main system, for allowing fast and accurate fixture configuration design in an interactive environment. Typical fixture configurations modeled using the fixture design module are presented in Fig. 3.

\section{Step 3 Material removal simulation}

For simulating the nonlinear thermostructural behavior of the workpiece due to its changing geometry during the transient metal removal process, a new, computationally efficient methodology has been devel- oped using the death and birth feature of the selected FEM elements. The material removal along the cutter feed direction is simulated by deactivating a set of elements equivalent to the cutter swept volume per feed-step (i.e., $\mathrm{Vol}_{\mathrm{mat}}$, obtained from Eq. 3) as demonstrated in Fig. 4(a-b). The feed-step corresponds to the distance between two adjacent cutter location points (dots shown in Fig. 1), and the feed-time to cover this distance $\left(T_{f}\right)$ is calculated from the specified cutter feed speed $\left(V_{f}\right.$, Eq. 1) and element length $\left(E_{l}\right)$ as given in Eq. 2.

$V_{f}=n * z * f_{t}$

where, $f_{t}$ is feed per tooth $(\mathrm{mm} /$ tooth $)$.
Fig. 6 Strategy to apply the intermittent machining loads as a function of the undeformed chip thickness

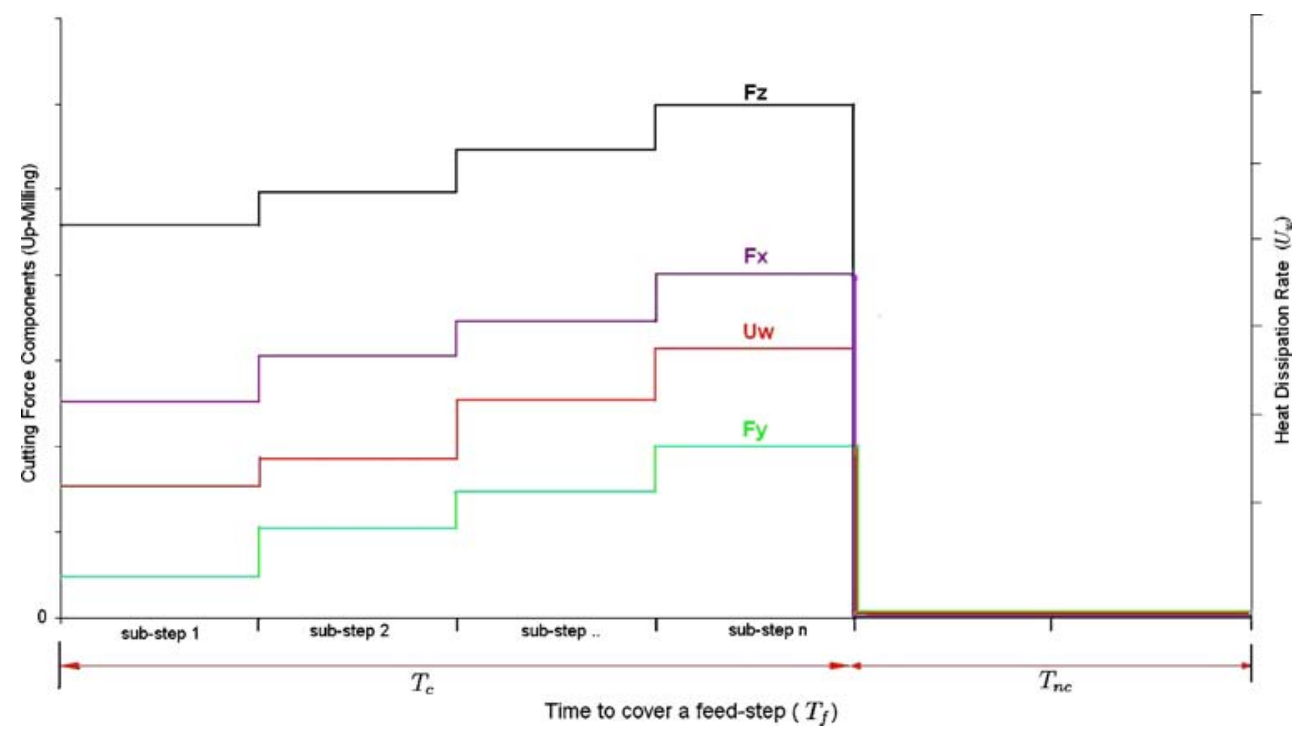


Table 2 Process plan and machining feature description for test part shown in Fig. 5 and calculated heat dissipation rate $\left.\left(U_{w}\right)\right)$

\begin{tabular}{lllllllllllll}
\hline $\begin{array}{l}\text { Feature ID/ } \\
\text { Operation No. }\end{array}$ & Type & $\begin{array}{l}\text { Datum } \\
(\mathrm{X}, \mathrm{Y}, \mathrm{Z})\end{array}$ & Dimensions $(\mathrm{mm})^{\mathrm{a}}$ & $f_{t}$ & $n$ & $a_{p}(\mathrm{~mm})$ & $a_{e}(\mathrm{~mm})$ & $D(\mathrm{~mm})$ & $z$ & $\beta$ & $\alpha$ & $U_{w}(\mathrm{~W})$ \\
\hline 1 & Step & $0,40,220$ & $60 \times 48 \times 12$ & 0.08 & 50 & 12 & 12 & 16 & 2 & $30^{\circ}$ & $9^{\circ}$ & 435 \\
2 & Step & $0,28,220$ & $56 \times 40 \times 24$ & 0.08 & 50 & 12 & 20 & 20 & 2 & $30^{\circ}$ & $9^{\circ}$ & 542 \\
3 & Step & $64,40,0$ & $60 \times 48 \times 12$ & 0.08 & 50 & 12 & 12 & 16 & 2 & $30^{\circ}$ & $9^{\circ}$ & 435 \\
4 & Pocket & $60,40,168$ & $56 \times 56 \times 16$ & 0.07 & 66 & 8 & 8 & 20 & 2 & $30^{\circ}$ & $9^{\circ}$ & 557 \\
5 & Pocket & $60,40,108$ & $56 \times 56 \times 16$ & 0.07 & 66 & 8 & 8 & 20 & 2 & $30^{\circ}$ & $9^{\circ}$ & 557 \\
6 & Slot & $64,40,140$ & $48 \times 48 \times 36$ & 0.05 & 66 & 12 & 12 & 20 & 2 & $30^{\circ}$ & $9^{\circ}$ & 447 \\
7 & Slot & $64,40,80$ & $48 \times 48 \times 36$ & 0.05 & 66 & 12 & 12 & 20 & 2 & $30^{\circ}$ & $9^{\circ}$ & 447 \\
8 & Slot & $64,28,24$ & $40 \times 52 \times 24$ & 0.05 & 66 & 12 & 20 & 20 & 2 & $30^{\circ}$ & $9^{\circ}$ & 447 \\
\hline
\end{tabular}

${ }^{\text {a }}$ Machining feature dimensions are given in length $\times$ width $\times$ depth format

Fig. 7 Procedure to perform transient coupled thermomechanical analysis

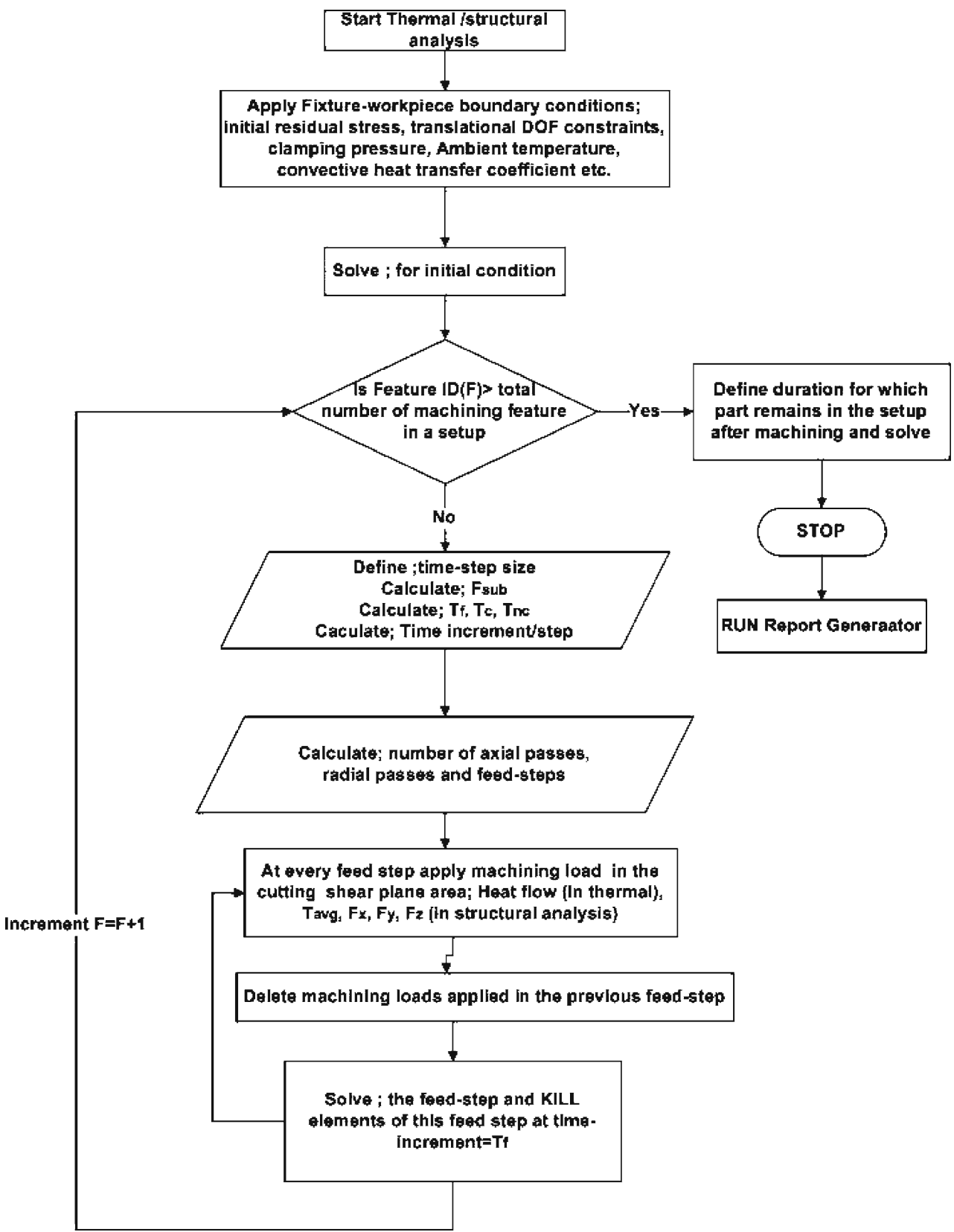




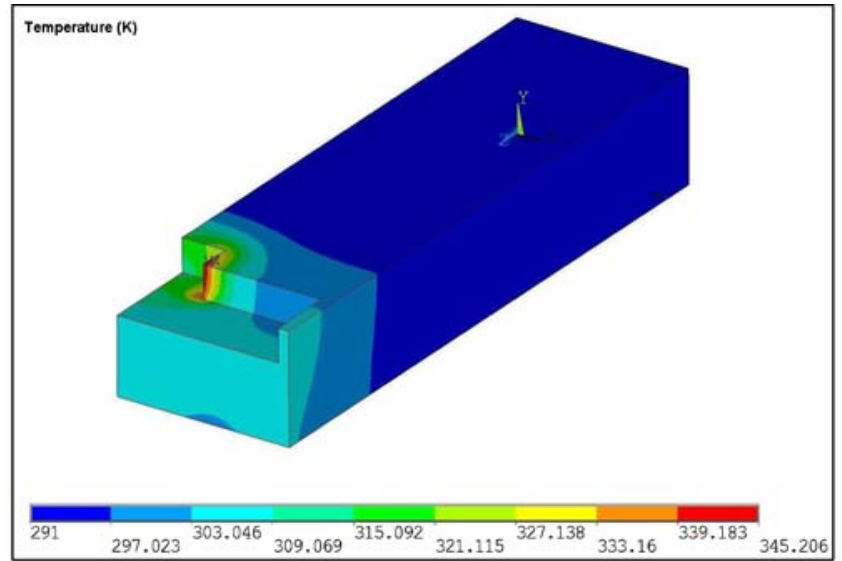

(a)

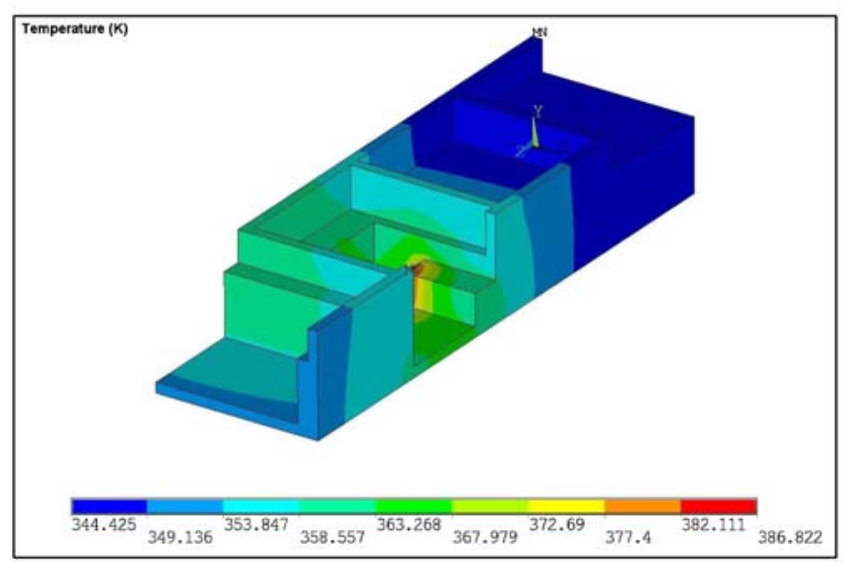

(c)

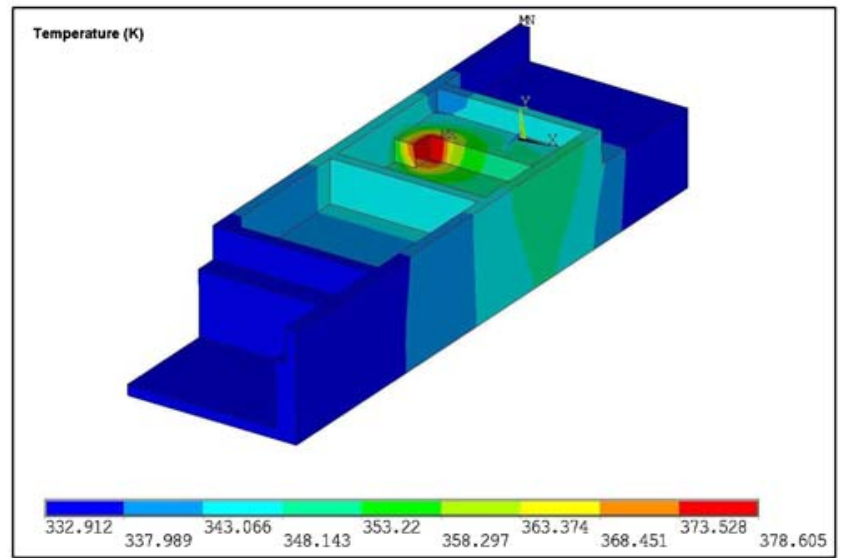

(b)

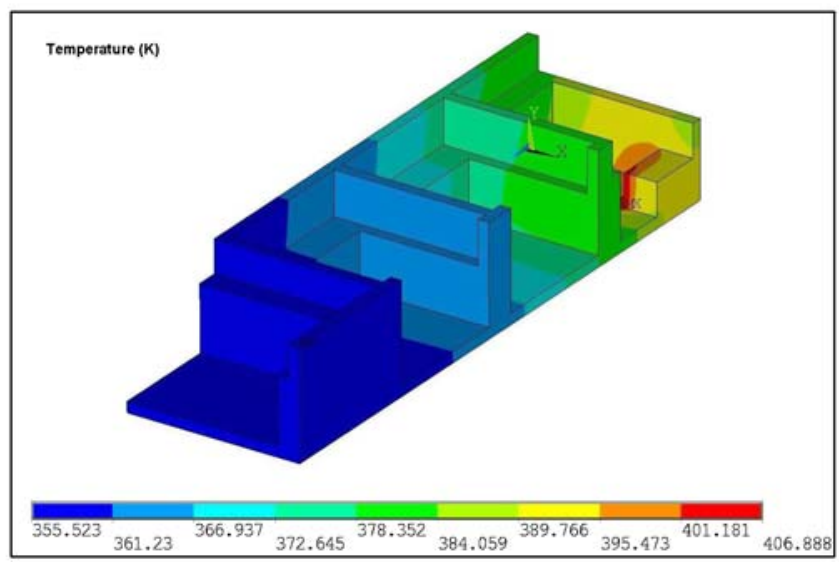

(d)

Fig. 8 Machining simulation for transient thermal analysis of the test part shown in Fig. 5 (process plan detailed in Table 2). a End of machining operation 1. b Machining operation 5 in progress. $\mathbf{c}$ Machining operation 6 in progress. d End of machining operation 8

The back and forth tool path strategy has been extensively used for simulating the machining of parts comprising features like, slots, steps, pockets, and nested features as shown in Fig. 5.

$T_{f}=\frac{E_{l}}{V_{f}}$

$\mathrm{Vol}_{\mathrm{mat}}=a_{p} * a_{e} * V_{f} * T_{f}=a_{p} * a_{e} * E_{l}$

$F_{\text {sub }}=\left\lceil\frac{a_{e}}{E_{l}}\right\rceil+1$

$T_{c}=\frac{\cos ^{-1}\left(\frac{D-2 a_{e}}{D}\right) * z}{2 \pi} * T_{f}$

$T_{\mathrm{nc}}=T_{f}-T_{c}$

Step 4 Determine transient temperature distribution in the workpiece
For determining the time-varying temperature distribution in the workpiece during the material removal process, a transient thermal analysis is conducted following the procedure demonstrated in Fig. 7, where, by applying the heat dissipation rate $U_{w}$ (obtained from Eq. 7) on nodes lying in the approximated cutting shear plane area (Fig. 4b) normal to the cutting tooth rotational trajectory (assumed to be a straight line, see Fig. 4a), temperature distribution in the workpiece over the entire cutting duration was computed for every feed step. The applied heat dissipation rate, i.e., $U_{w}$, is given by,

$U_{w}=\left(K_{c} * h_{m} * a_{p}\right) * V * H_{w}$

where $H_{w}$ is the heat dissipation coefficient for the workpiece, and its values for different machining features (under dry and wet machining conditions) were estimated experimentally. For simulating slot and step milling operations on Al-7075 workpiece material, the 


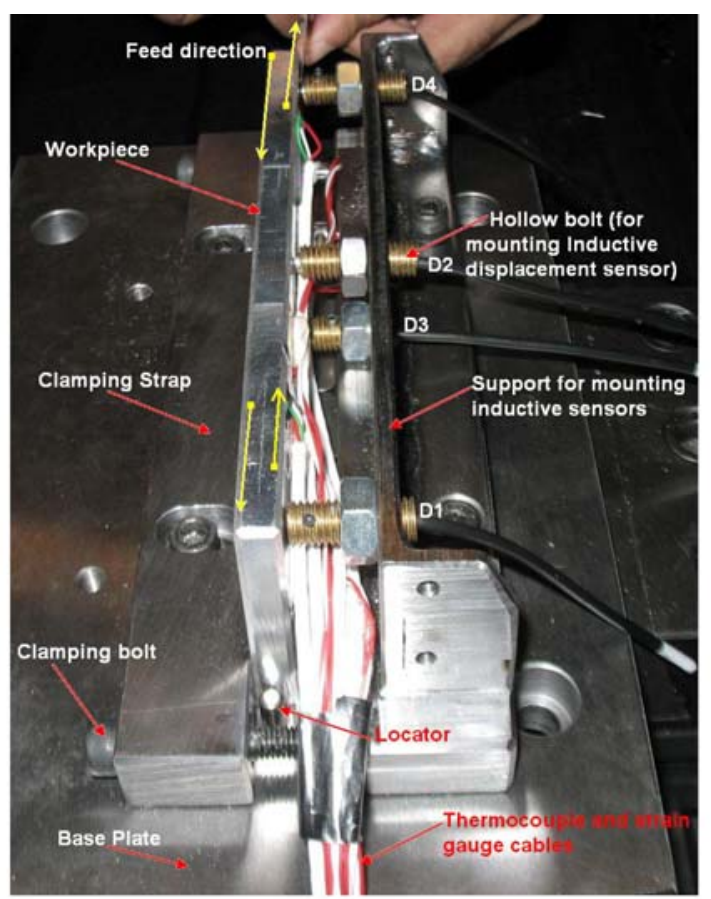

(a)

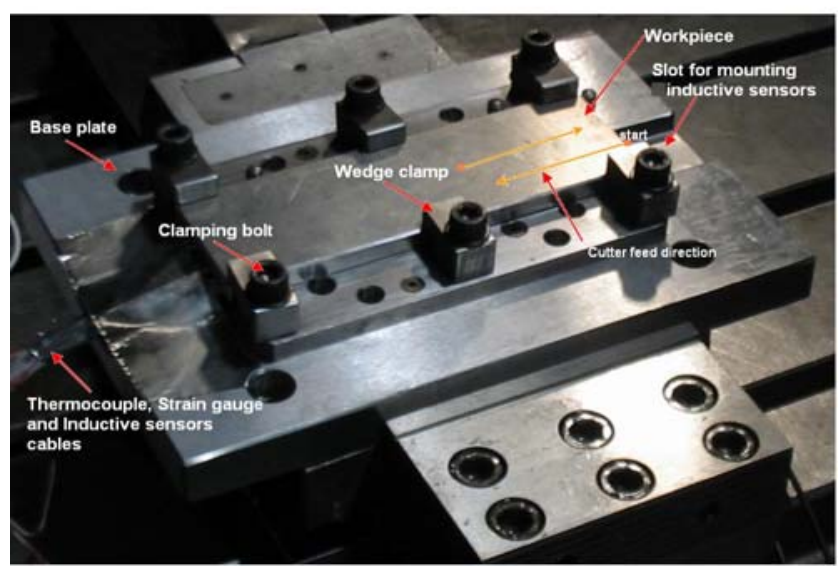

(b)

Fig. 9 Experimental setups for the test cases shown in Fig. 2. a Setup for machining a vertical rib. b Setup for machining a horizontal web

$H_{w}$ value was set to 0.3 and 0.075 under dry and wet machining conditions, respectively [21, 22].

In order to model the shear plane shifting along the radial direction (due to cutter rotation), each feed- step is further divided into a number of substeps ( $F_{\text {sub }}$, obtained from Eq. 4) as shown in Fig. 4b. Intermittent cutting effects are also introduced into the model by alternatively applying and removing machining loads (as a function of the undeformed chip thickness $\left(h_{m}\right)$ [6]) during the cutter-workpiece contact duration $\left(T_{c}\right.$, Eq. 5) and noncontact durations ( $T_{\text {nc }}$, Eq. 6), respectively, as depicted in Fig. 6. The developed thermal model was tested with complex part geometries similar to the one shown in Fig. 5, where a set of dry milling operations (i.e., air cooling with convection film coefficient $=7 \mathrm{~W} / \mathrm{m}^{2}-\mathrm{K}$ [21] and ambient temperature $=291 \mathrm{~K})$ as listed in Table 2 were simulated. The obtained transient temperature distributions at different machining stages are presented in Fig. 8a-d.

Step 5 Perform transient thermomechanical structural analysis

After the completion of the transient thermal analysis, the milling process transient structural analysis can be performed (using the procedure depicted in Fig. 7) by replacing the previously applied thermal boundary conditions with the structural boundary conditions like clamping loads (calculated using Eq. 8 for clamping bolts [14]), fixturing constrains, ambient temperature, etc., on the fixture-workpiece FEM model. The transient workpiece temperature distributions obtained from the thermal analysis are applied along with the cutting force components; $F_{x}, F_{y}$, and $F_{z}$ (obtained from the integrated cutting force module developed based on the approach given in [6]) acting along the feed, the axial and the radial directions, respectively, with a uniform distribution over the cutting shear plane area following the procedure discussed in step 4 and solved.

$F_{\text {clamp }}=\frac{T}{0.2 * D_{b}}$

where $F_{\text {clamp }}$ is the clamping force $(\mathrm{N}), T$ is the applied torque $(\mathrm{N}-\mathrm{mm})$, and $D_{b}$ is the bolt nominal diameter (mm).

Table 3 Test case description for the experimental validation of the proposed model

\begin{tabular}{llllllcllllll}
\hline Test case & $\begin{array}{l}\mathrm{m} / \mathrm{c} \\
\text { feature }\end{array}$ & Datum $(\mathrm{X}, \mathrm{Y}, \mathrm{Z})$ & $\begin{array}{l}\text { Dimensions } \\
(\mathrm{mm})^{\mathrm{a}}\end{array}$ & $f_{t}$ & $n$ & $a_{p}(\mathrm{~mm})$ & $a_{e}(\mathrm{~mm})$ & $D(\mathrm{~mm})$ & $z$ & $\beta$ & $\alpha$ & Coolant \\
\hline 1 & Step & $200,64,0$ & $198 \times 8 \times 40$ & 0.08 & 50 & 20 & 4 & 20 & 2 & $30^{\circ}$ & $9^{\circ}$ & $\mathrm{OFF}^{\circ}$ \\
2 & Step & $200,64,0$ & $198 \times 9 \times 32$ & 0.075 & 25 & 16 & 4.5 & 18 & 2 & $30^{\circ}$ & $9^{\circ}$ & $\mathrm{OFF}^{\circ}$ \\
3 & Slot & $200,10,30$ & $195 \times 40 \times 9$ & 0.074 & 50 & 4.5 & 10 & 16 & 2 & $30^{\circ}$ & $9^{\circ}$ & OFF \\
4 & Step & $200,64,0$ & $198 \times 9 \times 42$ & 0.09 & 67 & 14 & 4.5 & 16 & 2 & $30^{\circ}$ & $9^{\circ}$ & $\mathrm{ON}^{\circ}$ \\
\hline
\end{tabular}

${ }^{\mathrm{a}}$ Machining feature dimensions are given in length $\times$ width $\times$ depth format 
Table 4 Sensor location coordinates X,Y,Z (mm) with respect to origin "O" for test cases shown in Fig. 2

\begin{tabular}{llllllllll}
\hline Test case & T1 & T2 & T3 & D1 & D2 & D3 & D4 & S1 & S2 \\
\hline 1 & $(10,35,10)$ & $(140,35,10)$ & $(190,25,10)$ & $(10,55,10)$ & $(100,55,10)$ & $(100,30,10)$ & $(190,55,10)$ & $(50,35,10)$ & $(160,50,10)$ \\
2 & $(10,35,10)$ & $(140,35,10)$ & $(190,25,10)$ & $(10,55,10)$ & $(100,55,10)$ & $(100,30,10)$ & $(190,55,10)$ & $(50,35,10)$ & $(160,50,10)$ \\
3 & $(20,0,20)$ & $(180,0,35)$ & xx & $(190,0,20)$ & $(100,0,25)$ & xx & xx & $(60,0,25)$ & $(150,0,35)$ \\
4 & $(10,35,10)$ & $(140,35,10)$ & $(190,25,10)$ & $(10,55,10)$ & $(100,55,10)$ & $(100,30,10)$ & $(190,55,10)$ & $(50,35,10)$ & $(160,50,10)$ \\
\hline
\end{tabular}

\section{Step 6 Postprocess numerical results}

Finally, the obtained numerical results are processed by the developed report generator module and results are presented in the form of colored contours and graphs showing the transient temperature distribution and part deformations at specific nodal locations as shown in Figs. 8, 10, 11, 12, 13, 14, 15, 16, 17, 18, and 19. This module also allows the user to prepare 3D animated films for the visualization of the fixtureworkpiece transient temperature distribution, contact behavior, and the part deformations over the entire machining duration.

\section{Implementation and testing}

The Ansys parameteric design language programming features were extensively used for the implementation of the aforesaid modules of the developed FEM-based milling simulation tool. For testing its functional capabilities, the developed system was installed on a Windows workstation-equipped $\mathrm{Xeon}^{\mathrm{TM}} \mathrm{CPU} 3.00 \mathrm{GHz}$ and $2.00 \mathrm{~GB}$ of RAM configuration. The proposed model has been extensively tested using $2.5 \mathrm{D}$ prismatic parts with varying complexities provided by the KoBaS project [4] industrial partners, viz., (1) MCM s.p.a, Italy, a medium-size machining center manufacturing enterprise and (2) Quinson s.a., France, an aircraft part manufacturer. Looking at various aircraft structural parts available at their manufacturing sites, it was found that the thin-wall, large-size parts were mainly comprised of machining features like deep rectangular pockets, slots, and steps. Therefore, in order to test the adequacy of the developed model in handling complex part geometries and determining final machined part quality, two different test part sets were used, viz., (1) parts having multiple machining features per setup (similar to the one shown in Fig. 5) and (2) with one or two machining features. Using the same test cases, practical experiments were also performed and various measurements (at different workpiece locations) were made to obtain transient temperature distribution profiles, part deflections, and stress profiles using appropriate transducers over the entire cutting duration. The next sections detail the experimental validation of the proposed model, followed by results and discussions.

\section{Experimental verification}

In the presented work, a detailed experimental analysis was also carried out with the help of our industrial partner MCM s.p.a, Italy, for validating the numerical results, namely, the workpiece (1) temperature distributions, (2) displacements, and (3) stresses induced during the metal removal process. For measuring the workpiece temperature distribution, part deflection, and stresses, thermocouples, Keyence EX305 inductive displacement sensors, and HBM $350 \Omega$ strain gauges were employed, respectively. A total of 14 tests on Al-7075 workpiece material were performed using a three-axis SELCA controller vertical spindle milling center under dry and wet machining conditions. On each raw-stock, thermocouples and strain gauges were bonded at different locations and inductive sensors (having measuring distance limit of $1.0 \mathrm{~mm}$ ) were placed $0.5 \mathrm{~mm}$ apart from the workpiece surface through hollow bolts mounted on specially designed fixtures (as shown in Fig. 9), and a multipass (both in axial and radial directions) machining operation was performed for generating a pocket, a slot, or a step feature. Table 3 details the operation plan for a set of four test cases used in the present experimental analysis. For test cases 1, 2, and 4, the experimental setup shown in Fig. 9a was used for generating a vertical rib
Table 5 Element size ( $\mathrm{mm})$ for generating adaptive Mesh of the raw stock

\begin{tabular}{llllllll}
\hline Test case & \multicolumn{2}{l}{ Cut volume } & & & \multicolumn{3}{l}{ Uncut volume } \\
\cline { 2 - 3 } & $E_{l}$ & $E_{l}$ & $E_{h}$ & & $E_{l}$ & $E_{l}$ & $E_{h}$ \\
\hline 1 & 4 & 4 & 4 & 4 & 2 & 4 \\
2 & 4.5 & 4.5 & 4 & 4.5 & 1 & 4 \\
3 & 5 & 5 & 4.5 & 5 & 5 & 1 \\
4 & 4.5 & 4.5 & 3.5 & 4.5 & 1 & 3.5 \\
\hline
\end{tabular}


Table 6 Computed cutting force components and heat dissipation rate for the test cases given in Table 3

\begin{tabular}{lllll}
\hline Test case & $F_{x}(\mathrm{~N})$ & $F_{y}(\mathrm{~N})$ & $F_{z}(\mathrm{~N})$ & $U_{w}(\mathrm{~W})$ \\
\hline 1 & 750 & 111 & 235 & 904 \\
2 & 757 & 115 & 301 & 305 \\
3 & 302 & 62 & 433 & 150 \\
4 & 818 & 126 & 374 & 190 \\
\hline
\end{tabular}

through machining a step feature, whereas in test 3 , the experimental setup shown in Fig. 9b, along with a slot machining operation, was used for generating a horizontal web feature. In all experiments, a raw-stock of dimensions $200 \times 64 \times 10 \mathrm{~mm}$ was used and parts were machined without coolant for tests $1-3$ and with coolant for test 4 . For measuring the temperature, deflection, and stress profiles during cutting, in tests 1,2 , and 4 , three thermocouples (T1, T2, and T3), four displacement inductive sensors (D1, D2, D3, and D4), and two strain gauges (S1 and S2) were employed (as shown in Figs. 3a and 9a), and for test 3, a total of six sensors (T1, T2, D1, D2, S1, and S2), as depicted in Figs. 3b and 9b, were mounted on the workpiece unmachined surface. Sensor location coordinates for the used test cases are listed in Table 4. During the experiments, signals from all the sensors were acquired simultaneously by the MDT2 (displacement and temperature data acquisition system) and CATMAN (strain data acquisition system) software installed on two laptops.

In order to verify the numerical results, the same tests were simulated using the developed milling simulation software under identical machining conditions. First, the fixture-workpiece FEM models for the considered test part geometries as shown in Fig. 3a (for
Fig. 10 Predicted and measured temperature profiles at $\mathrm{T} 1$ for test cases 1 and 2 in Table 3. a Test case 1 (without coolant). b Test case 2 (without coolant)

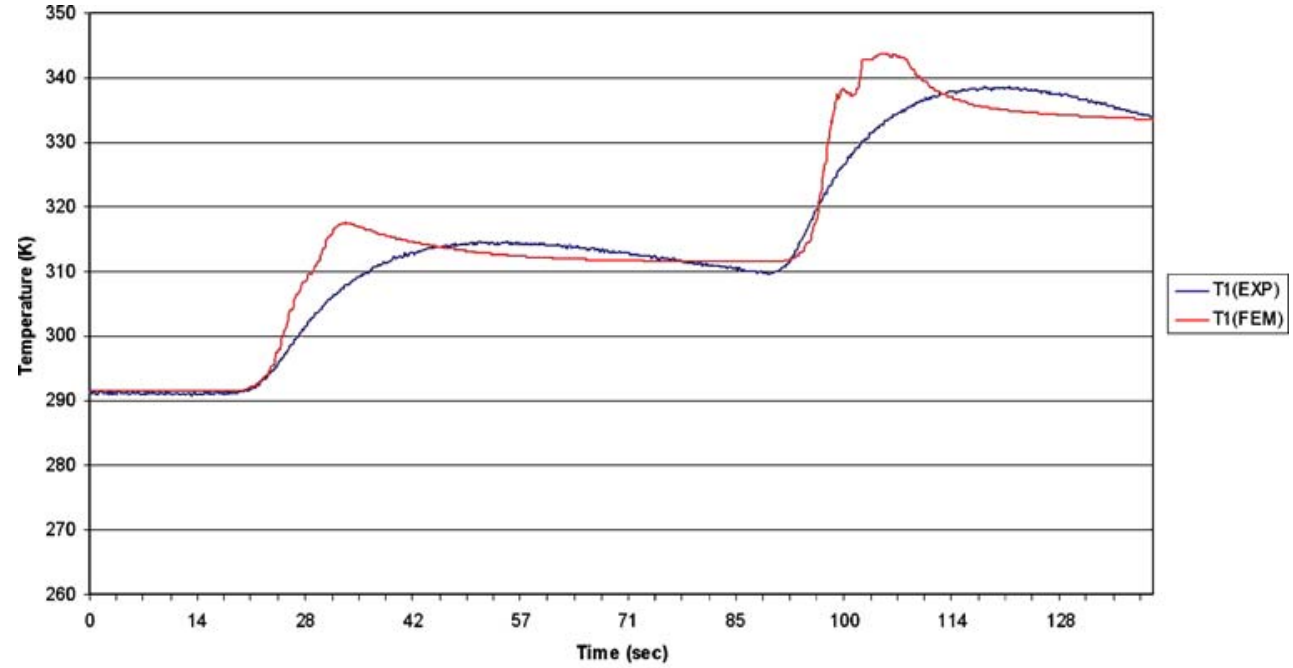

(a)

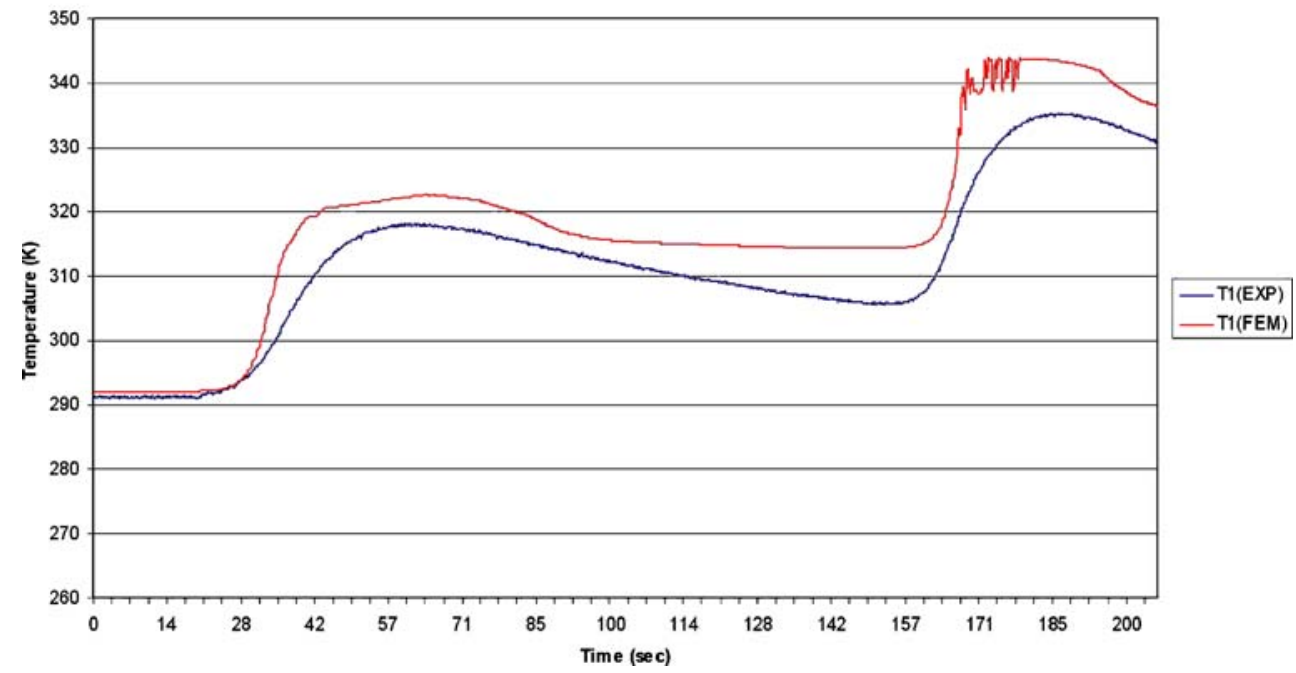

(b) 
Fig. 11 Predicted and measured temperature profiles at $\mathrm{T} 1$ for test cases 3 and 4 in Table 3. a Test case 3 (without coolant). b Test case 4 (with coolant)

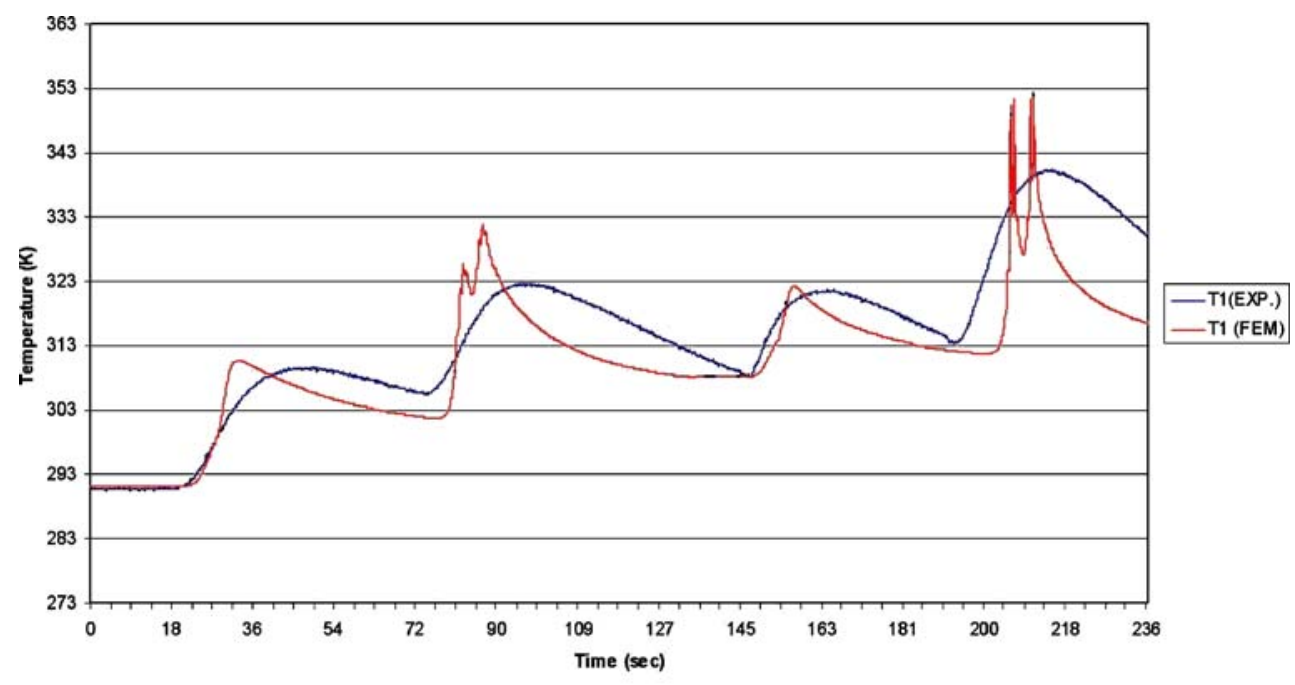

(a)

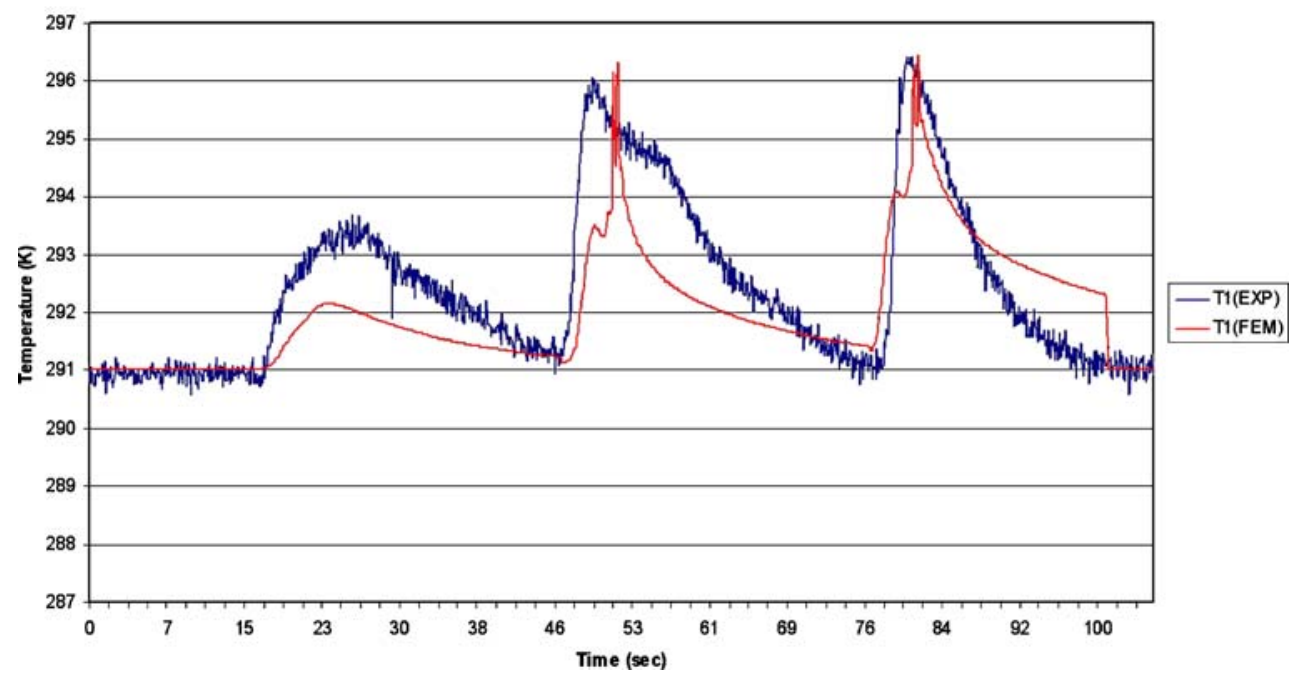

(b) tests 1, 2, and 4) and Fig. 3b (for test 3) were created using the developed fixture design module. In all the test cases clamping bolts of diameter $10 \mathrm{~mm}$ were used. In order to reduce the computational time, the FEM model of the raw-stock for each test case was modeled using the adaptive mesh approach with element size listed in Table 5. The meshing of the fixture elements and contact surfaces were performed automatically using the ANSYS program automesh capabilities. After applying appropriate thermomechanical boundary constrains (sequentially) on the fixture-workpiece configuration, the material removal process was simulated using the computed peak load values as presented in Table 6. A clamping load of $1,000 \mathrm{~N}$ (using $T=2,000 \mathrm{~N}$ $\mathrm{mm}$ for one-hand operation [14]) was applied on each bolt in all the test cases. In test 4 , the rise in convective heat transfer rate due to the application of coolant was modeled by applying a convective film coefficient of $2,700 \mathrm{~W} / \mathrm{m}^{2}-\mathrm{K}$ [21] and coolant temperature of $291 \mathrm{~K}$ on the workpiece surfaces exposed to the coolant jet. The obtained nodal results, i.e., temperature profiles, $\mathrm{Z}$ displacement $(\mathrm{Uz})$ contours and the von misses stress (SEQV) contours at respective sensor locations for the used test cases are presented in Figs. 10-19.

\section{Results and discussions}

In the first experimental validation phase of the developed FEM-based milling simulation model, simple test part geometries needing a pocket, a step, or a slot machining operation were considered to (1) simplify the experimental setup design, (2) gain in-depth under- 
Fig. 12 Predicted and measured deflection profiles for test case 1 in Table 3 . a Predicted $\mathrm{Z}$ deflection profiles for test case 1 at D4. b Measured $\mathrm{Z}$ deflection profiles for test case 1 at D4

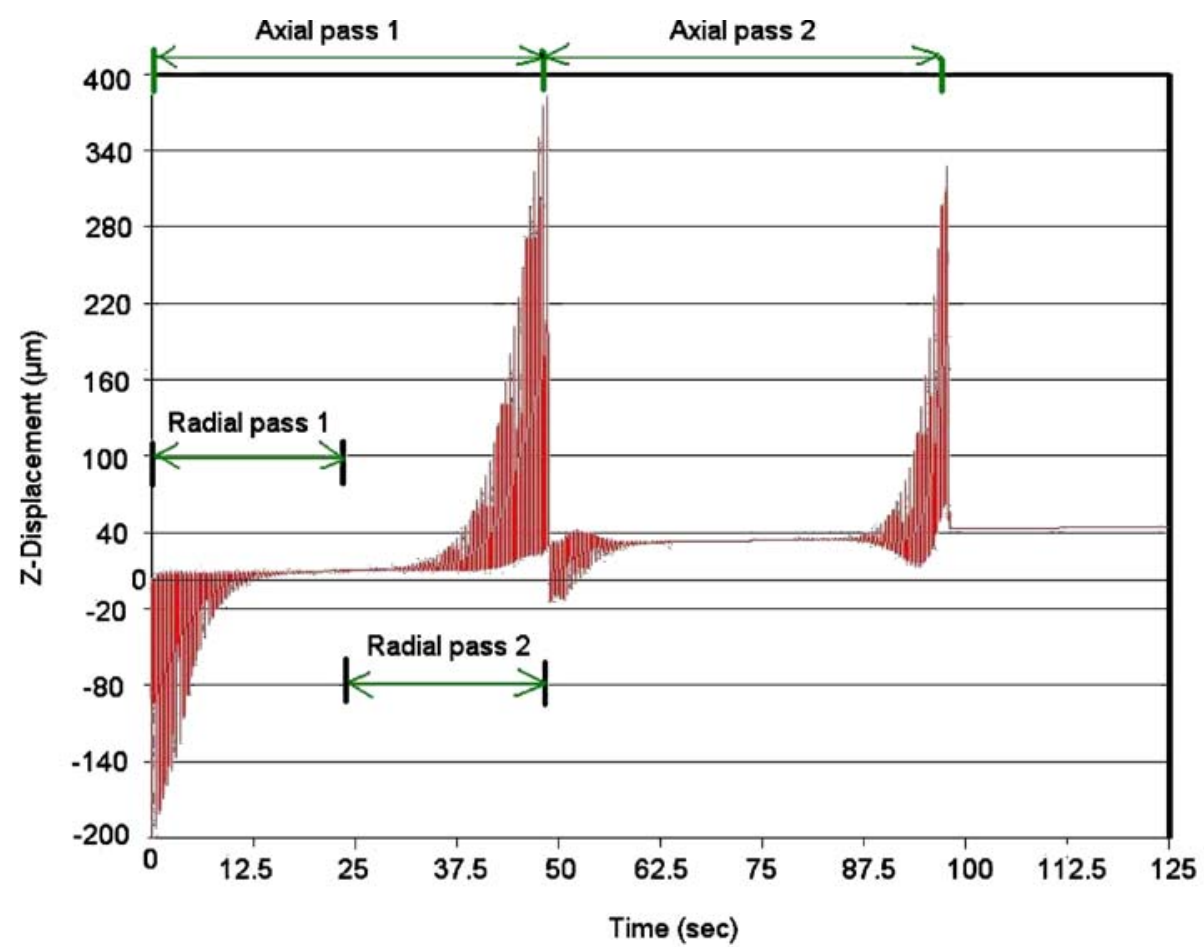

(a)

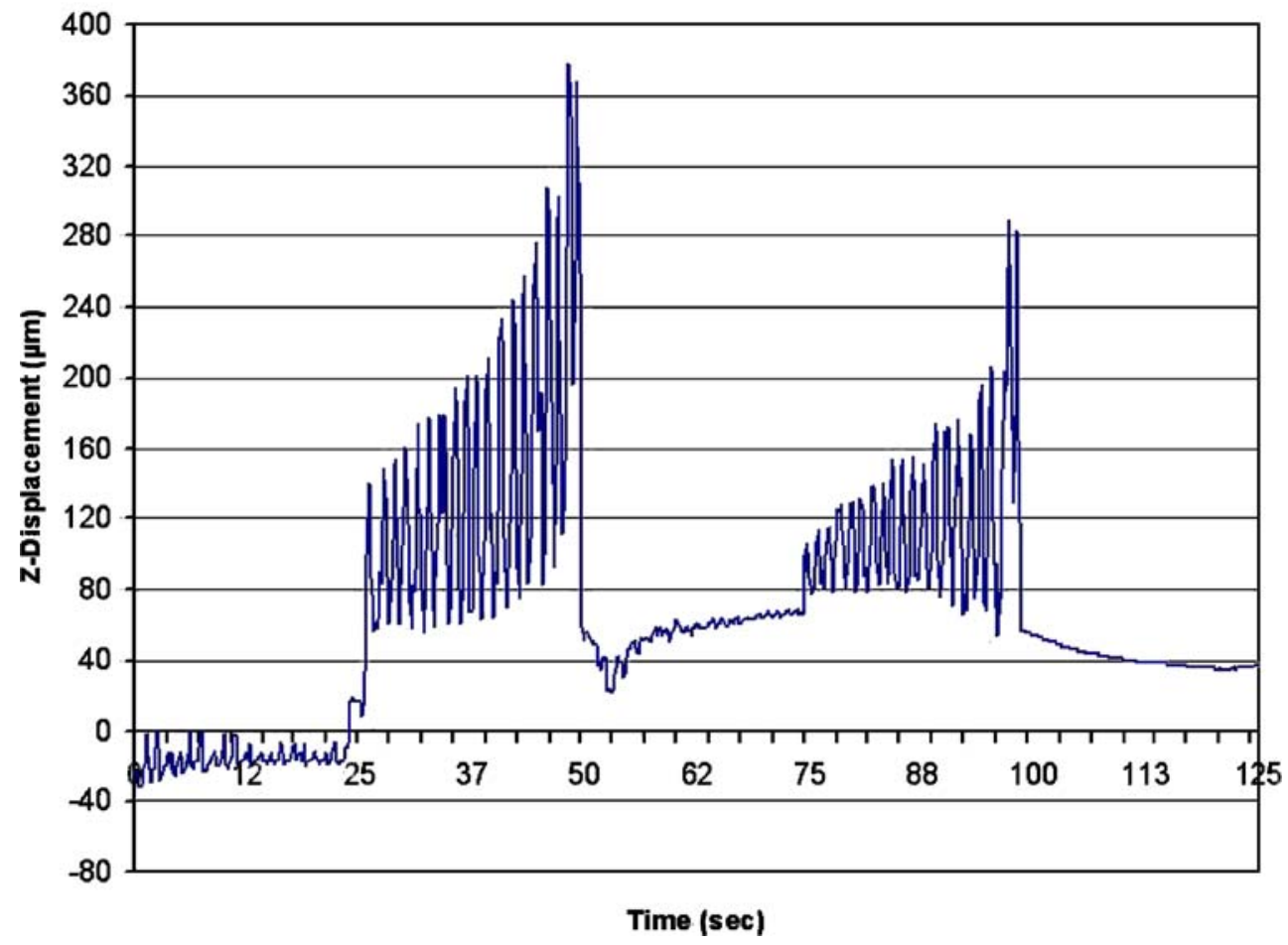

(b) standing of the workpiece behavior during machining, and (3) have better interpretation of the measured results. The predicted and measured temperature profiles for tests $1-4$ at $\mathrm{T} 1$ thermocouple location are presented in Figs. 10 and 11. It is observed that both predicted and measured temperature profiles in all the test cases show similar trends over the entire machining duration and reached the same peak values. Referring to Figs. 10 and 11 , the sudden rise and fall in the temperature profiles represents the nearness of the moving heat source 
Fig. 13 Predicted and measured deflection profiles for test case 2 in Table 3. a Predicted $\mathrm{Z}$ deflection profiles for test case 2 at D1. b Measured $\mathrm{Z}$ deflection profiles for test case 2 at D1

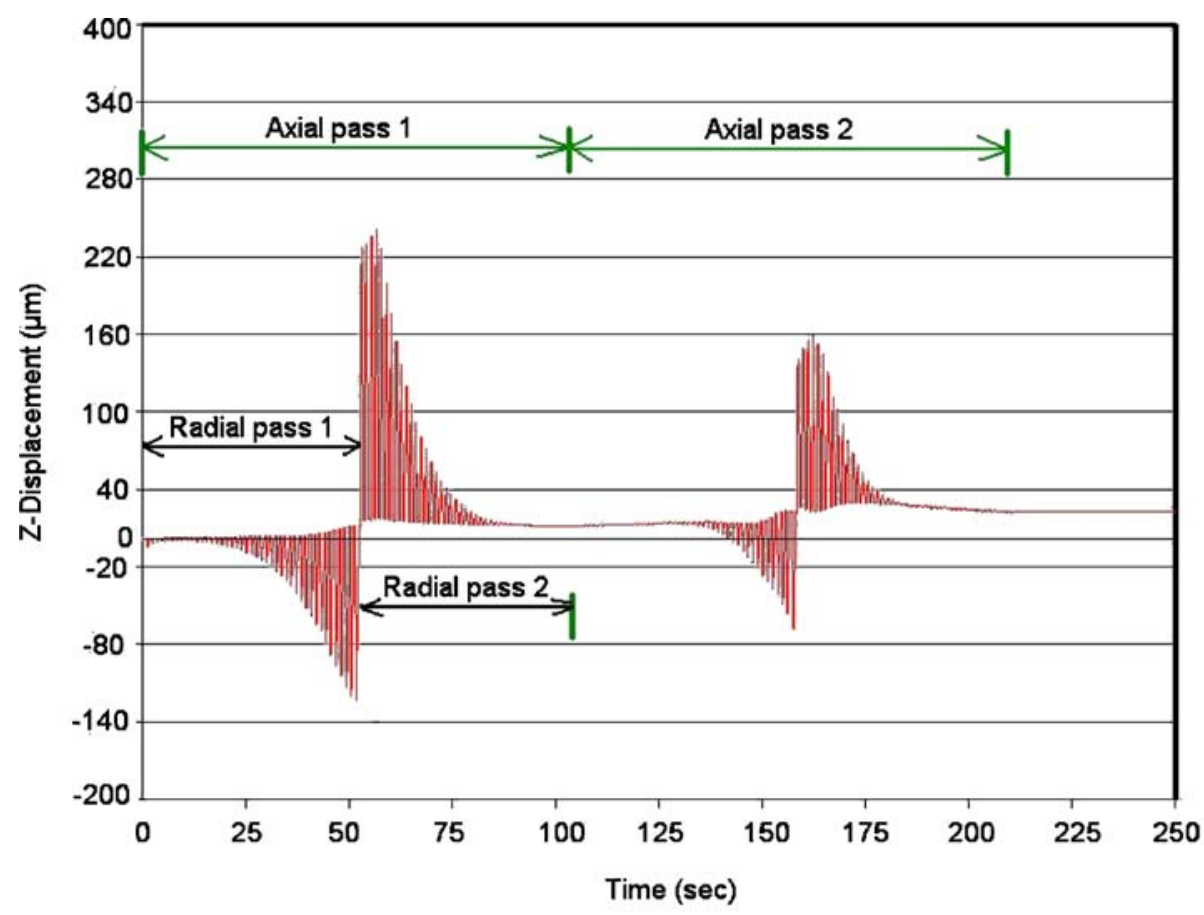

(a)

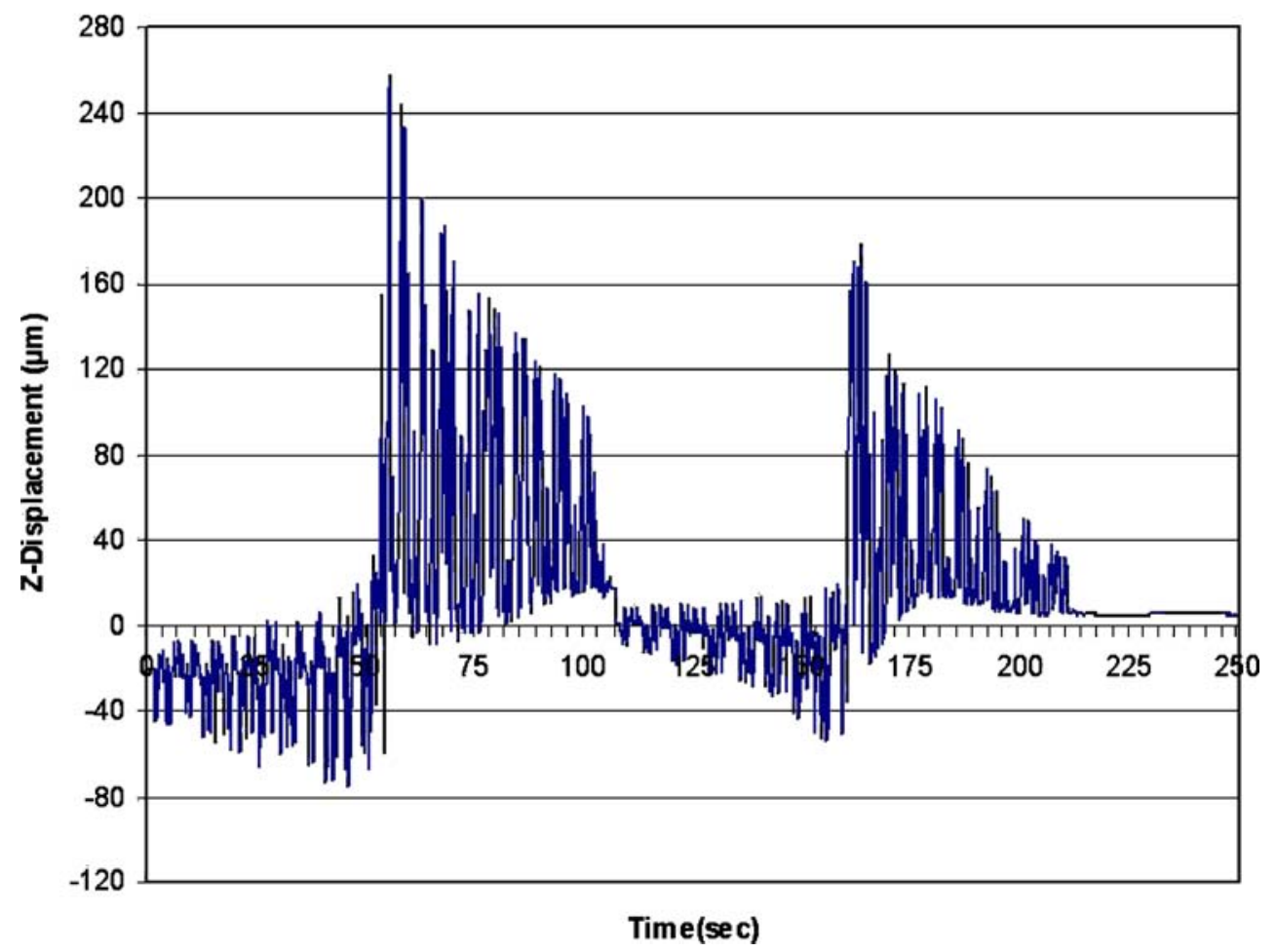

(b) (cutter) to the measuring points during the axial and radial cutting passes. A small difference in the slopes of the predicted and measured temperature profiles can be seen, which is mainly due to machining load application strategy (as discussed in Section 4) developed in the present work for enhancing computational efficiency of the proposed model. Looking at Fig. 11b, it is evident that, during wet machining (i.e., with coolant), the heat dissipation rate increase due to forced convection, and thus, the rise in workpiece temperature, was 
Fig. 14 Predicted and measured deflection profiles for test case 3 in Table 3. a Predicted Y deflection profiles for test case 3 at D2. b Measured $\mathrm{Y}$ deflection profiles for test case 3 at D2

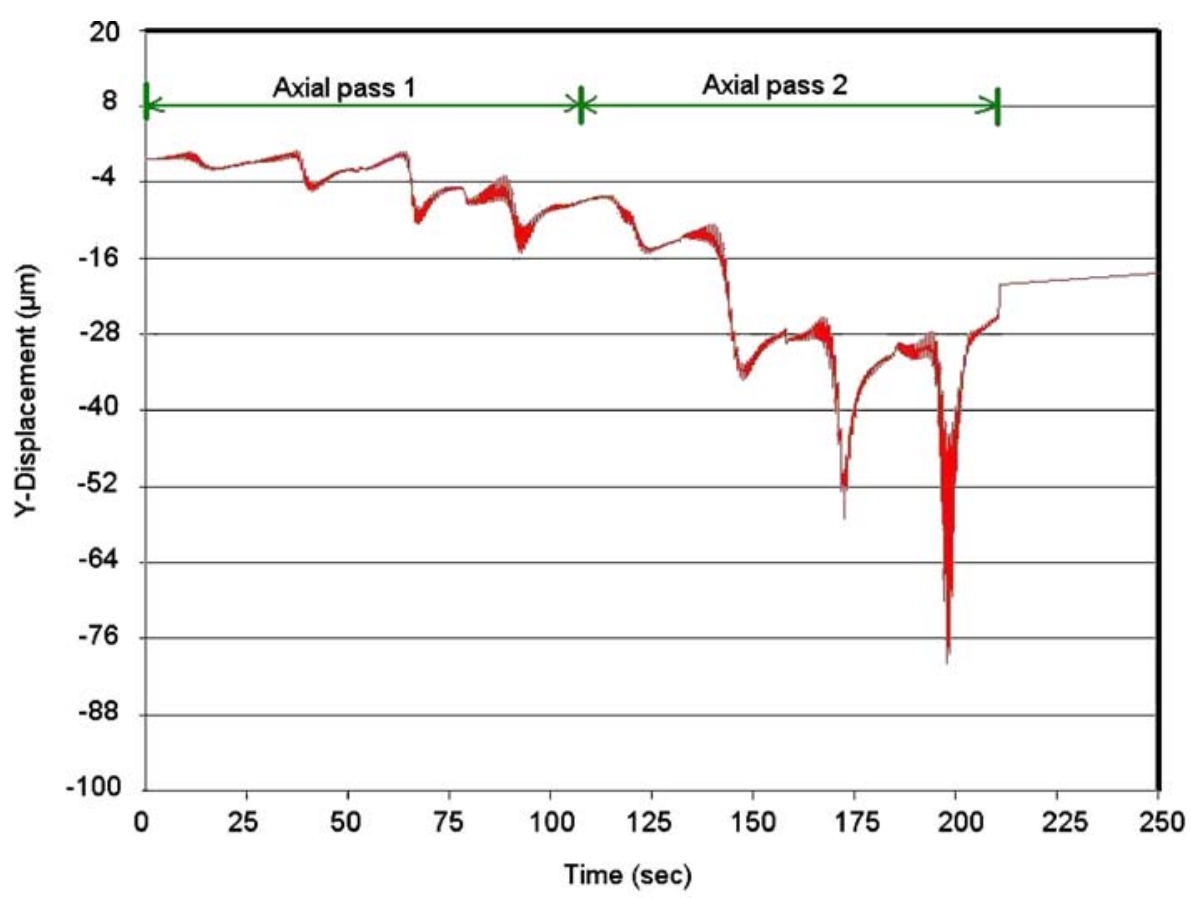

(a)

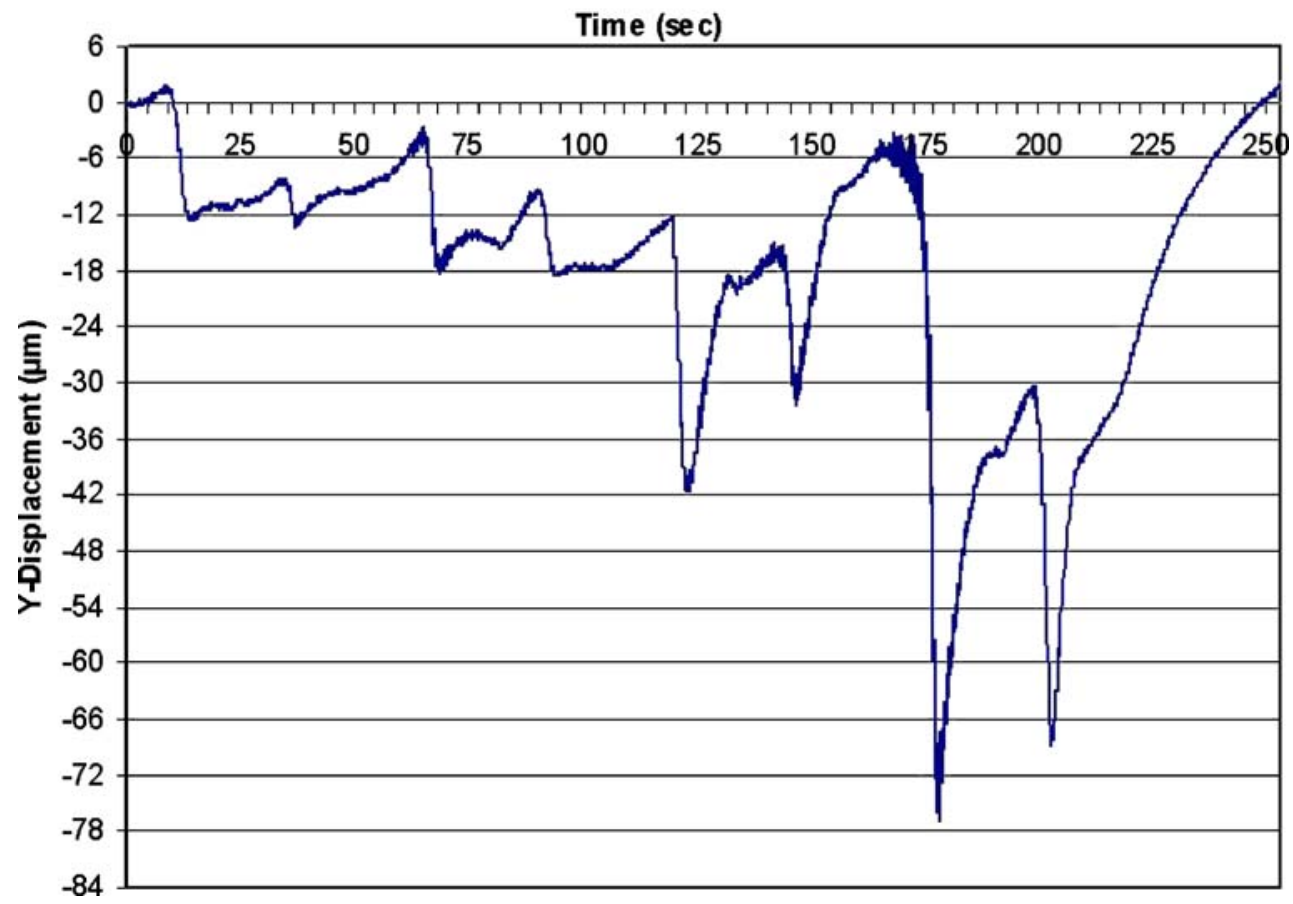

(b) found to be negligible except for instances when the cutter was closer to the measuring sensor locations as seen in the plotted temperature profiles. On the contrary, in dry machining (in tests 1-3), the temperature profile rises gradually due to the low convective heat transfer rate (i.e., natural convection) and continuous heat flow into the workpiece.
For tests 1-4, part deflections during machining were examined both experimentally and numerically, and the results are presented in Figs. 12-15. Referring to Figs. 12-15, it is seen that the deflection profiles obtained numerically and experimentally at different measuring points show identical behavior. For instance, looking at Fig. 13, it is evident that the 
Fig. 15 Predicted and measured deflection profiles for test case 4 in Table 3. a Predicted $\mathrm{Z}$ deflection profiles for test case 4 at D1. b Measured $\mathrm{Z}$ deflection profiles for test case 4 at D1

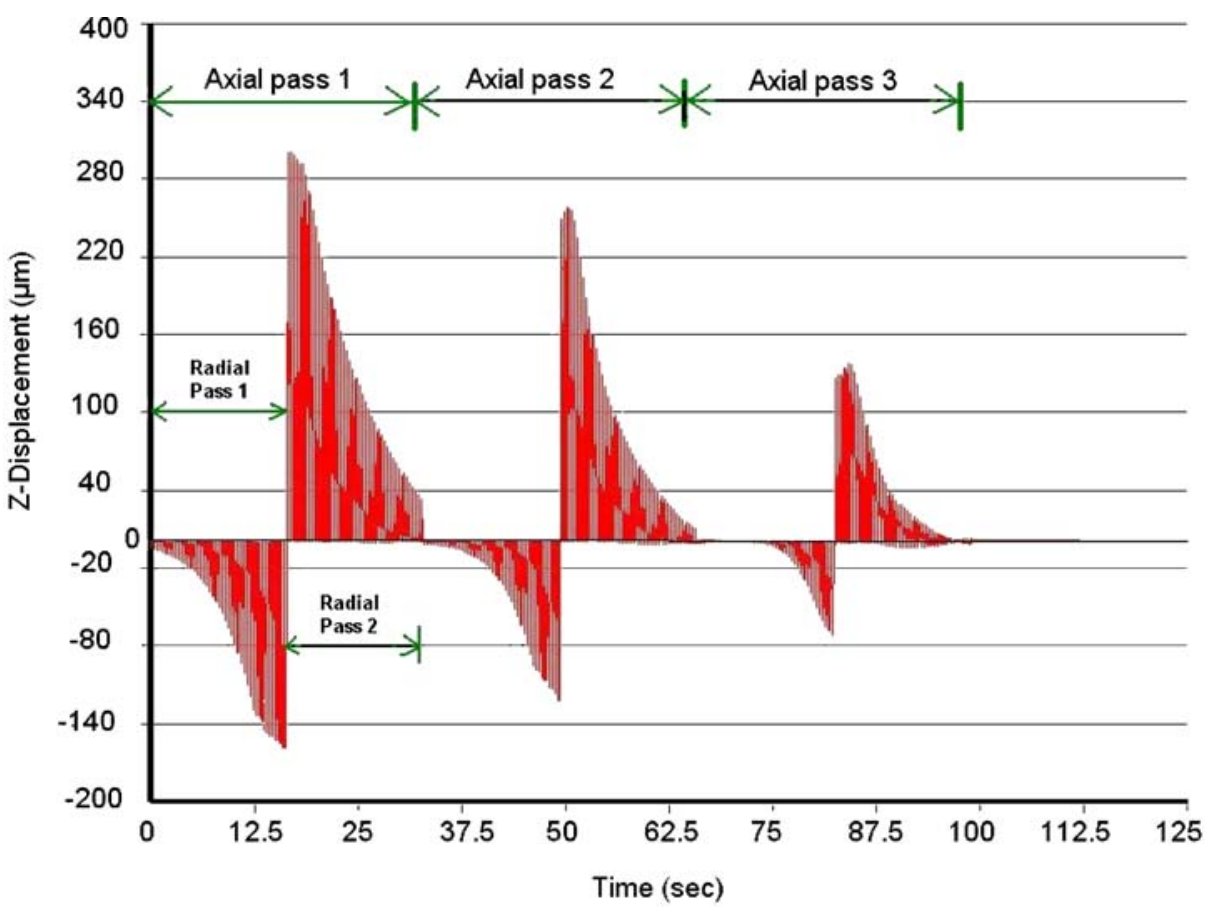

(a)

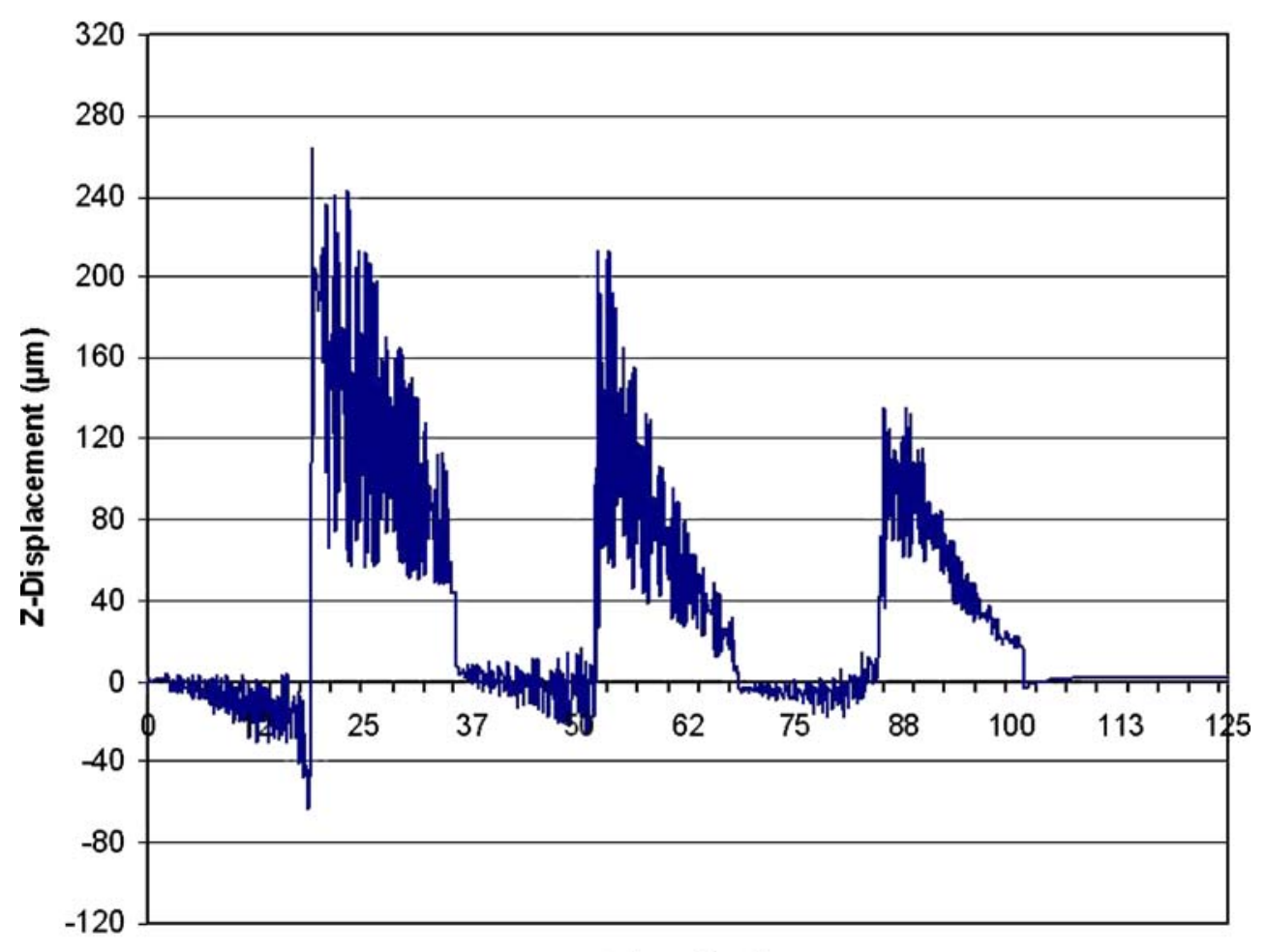

Time (sec)

(b) part $\mathrm{Z}$ deflection sensed by D1 increases as the cutter moves towards the sensor and decays as the cutter passes by. Similar trends were observed for sensor D4, as shown in Fig. 12 (for test 1), and D1 in test
4 (Fig. 15). For test case 3, the horizontal-web deflections were measured along the "Y" direction (see Figs. $3 b$ and $9 b$ ). In test 3 , as the cutter moves from the first axial pass to the second the part, rigidity 
Fig. 16 Predicted and measured Von Mises stress for test case 1 in Table 3. a Predicted Von Mises stress profiles for test case 1 at $\mathrm{S} 2$. b Measured Von Mises stress profiles for test case 1 at S2

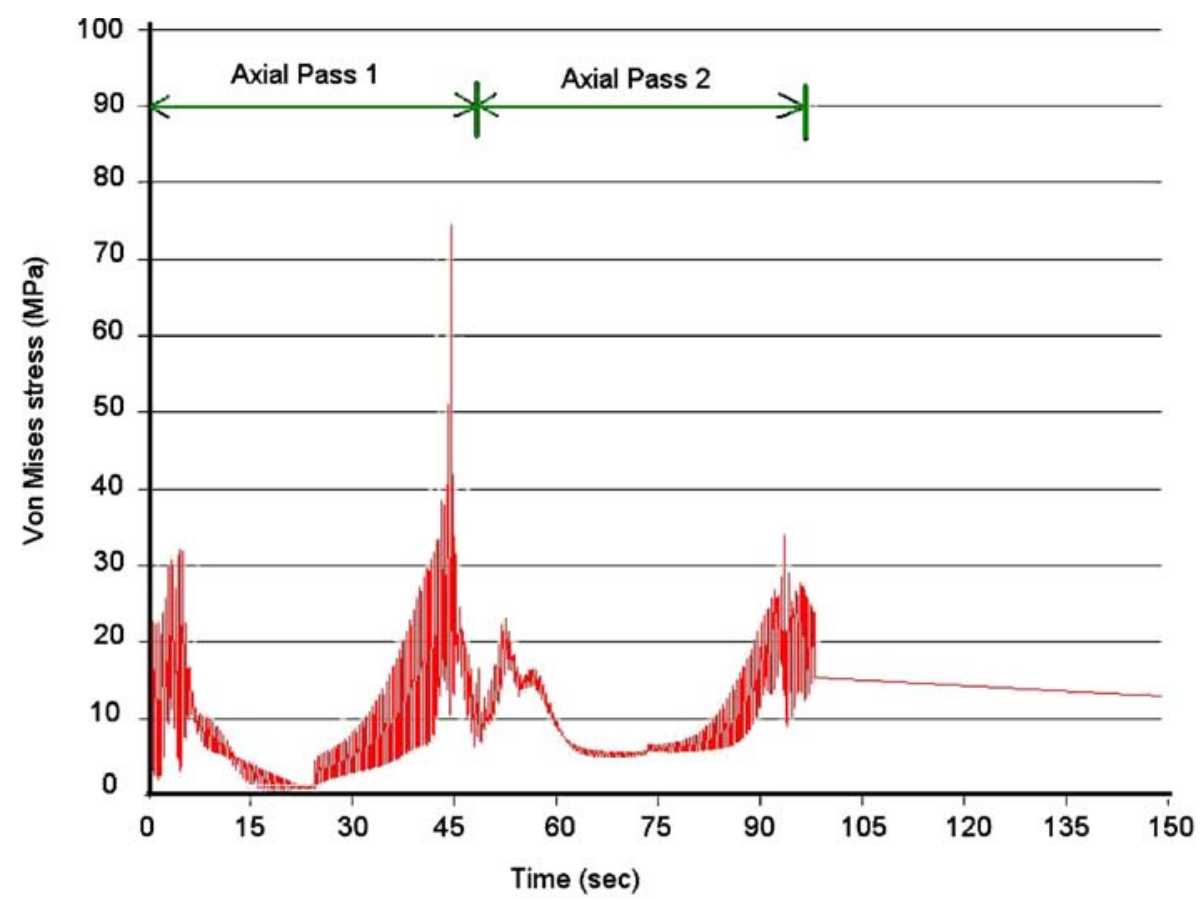

(a)

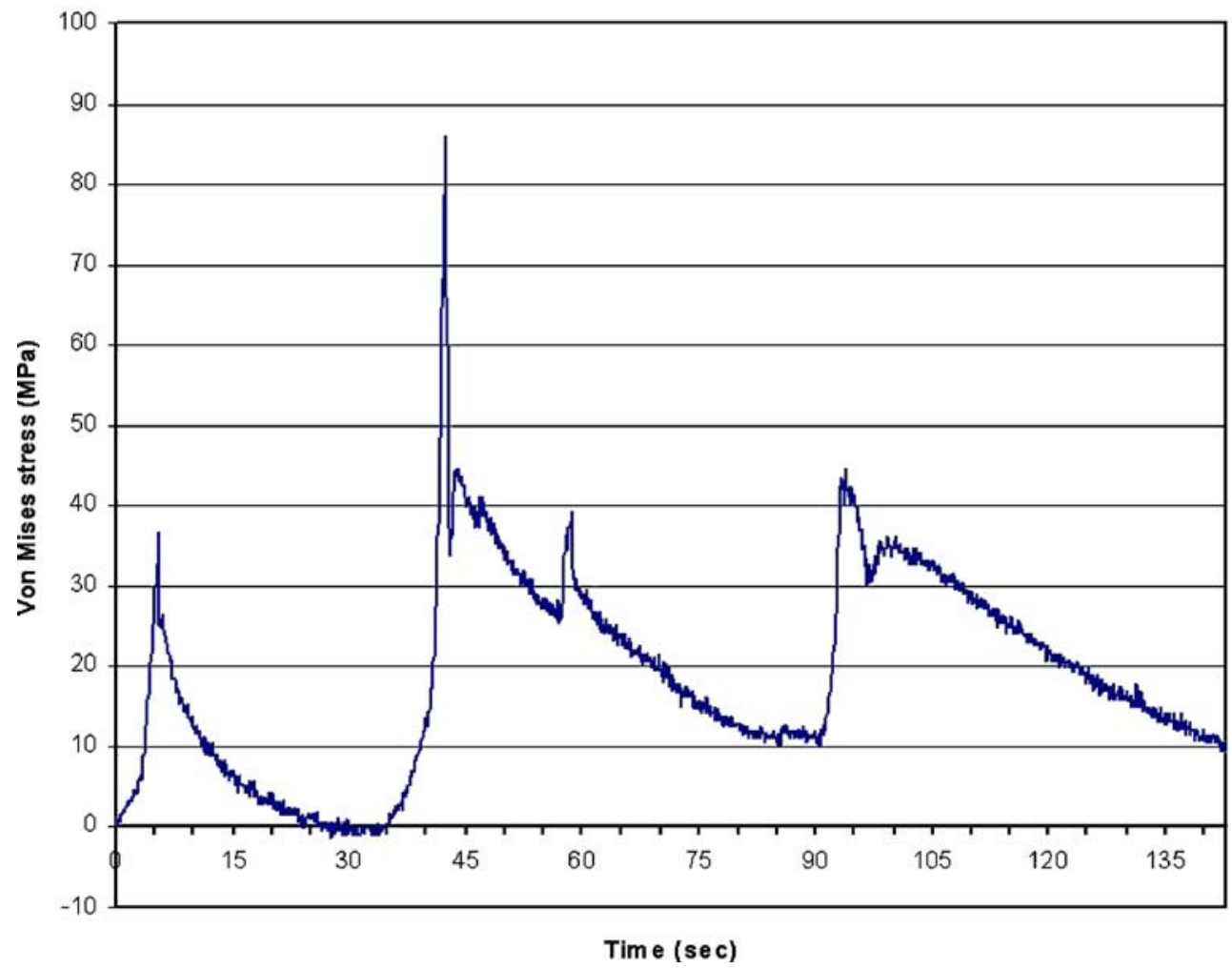

(b) decreases, causing much higher deflections compared to the first pass as seen in Fig. 14. Also, in Figs. 12, 13, and 15 , the deflection amplitude during the second radial pass is higher compared to the first for two reasons, viz., (1) decreased part rigidity and (2) cutting force radial $\left(F_{z}\right)$ component acted along the $+\mathrm{Z}$ direction. The cyclic fluctuations in the deflection contour (as observed in Figs. 12-15) are mainly due the application 
Fig. 17 Predicted and measured Von Mises stress for test case 2 in Table 3. a Predicted Von Mises stress profiles for test case 2 at S1. b Measured Von Mises stress profiles for test case 2 at $\mathrm{S} 1$

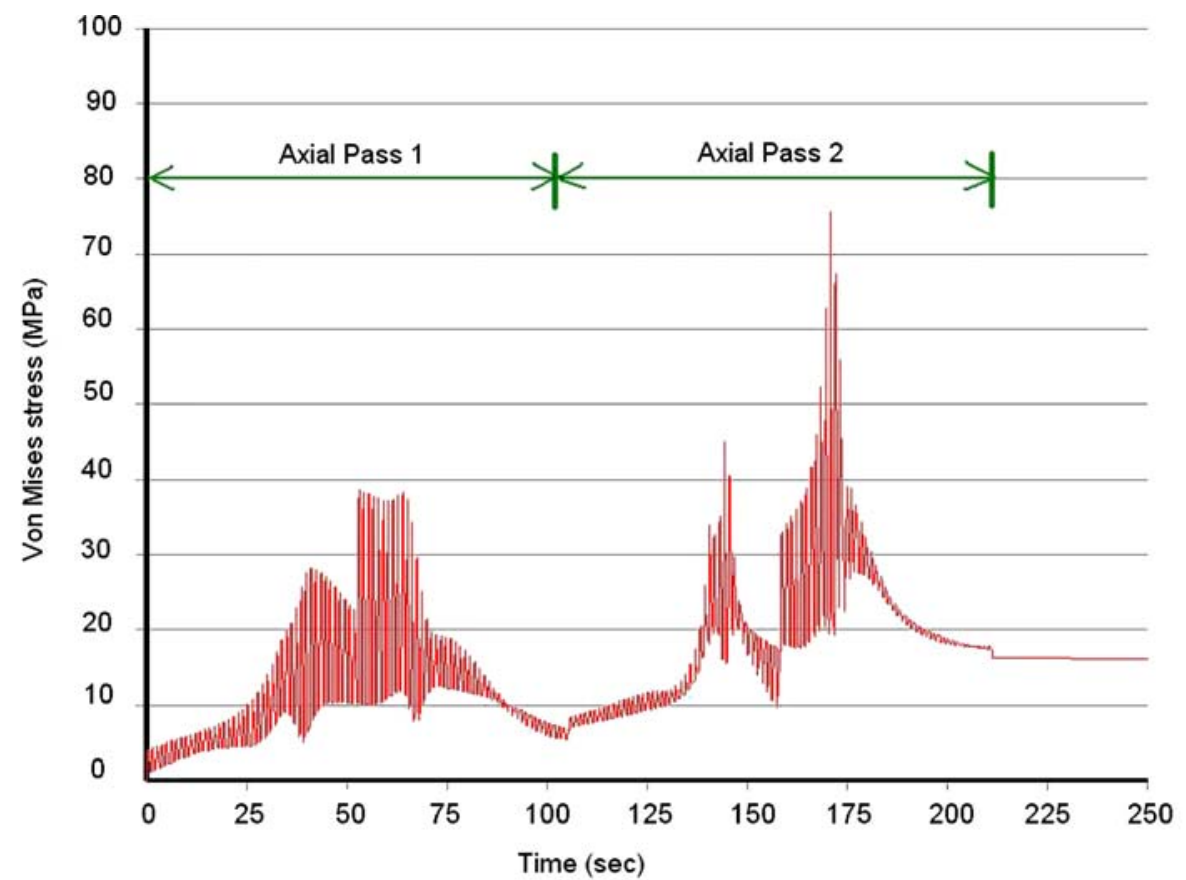

(a)

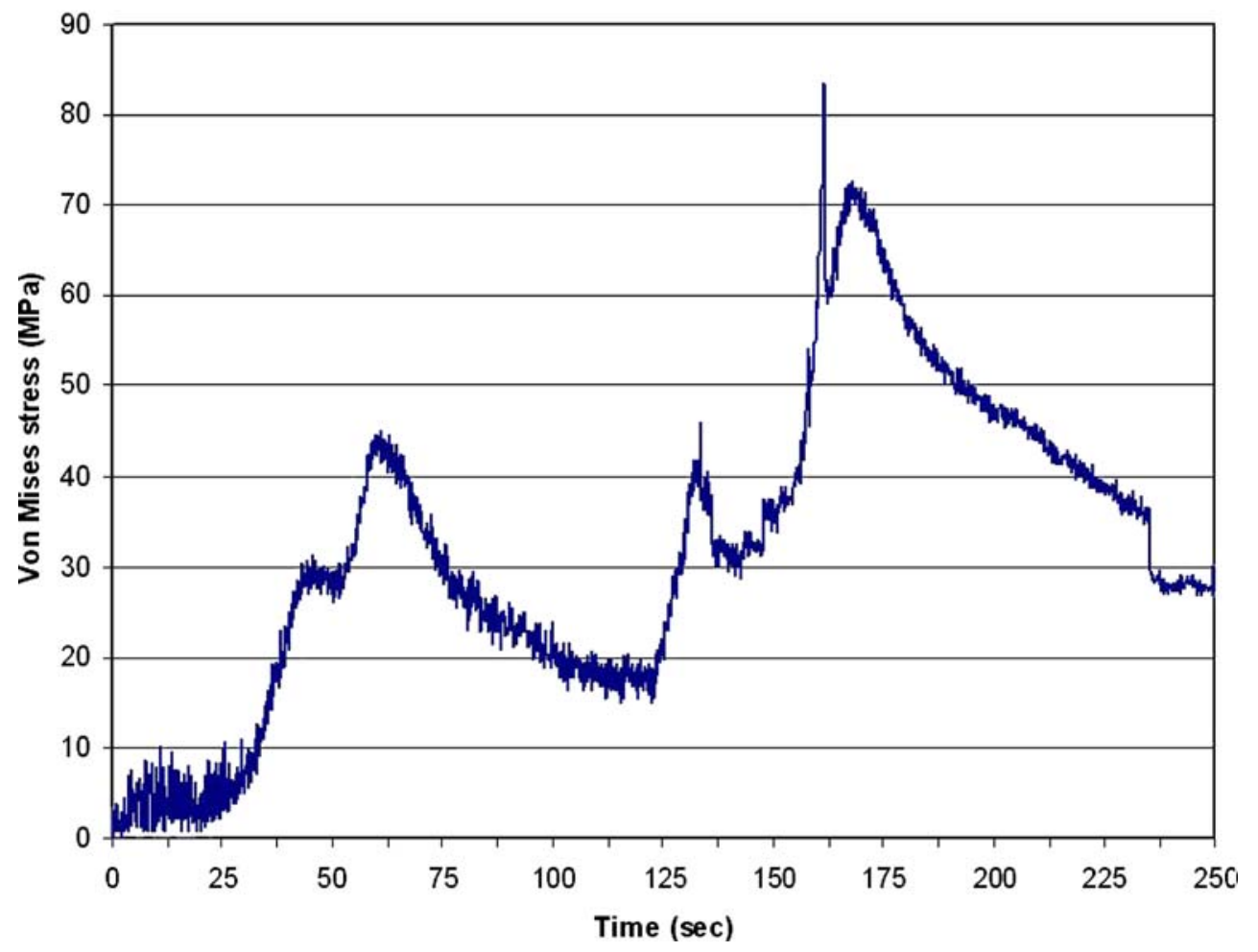

(b) and removal of the cutting forces during the cutter workpiece contact and noncontact durations.

In the present work, part deformations during machining were also analyzed both experimentally and numerically and the obtained Von Mises stress profiles for the used test cases are depicted in Figs. 16-19. Looking at Figs. 16-18, the gradual rise in the stress profile and the cyclic fluctuations shows the influence of thermal and mechanical loads, respectively, whereas, in test 4 , the mechanical 
Fig. 18 Predicted and measured Von Mises stress for test case 3 in Table 3. a Predicted Von Mises stress profiles for test case 3 at S2. b Measured Von Mises stress profiles for test case 3 at S2

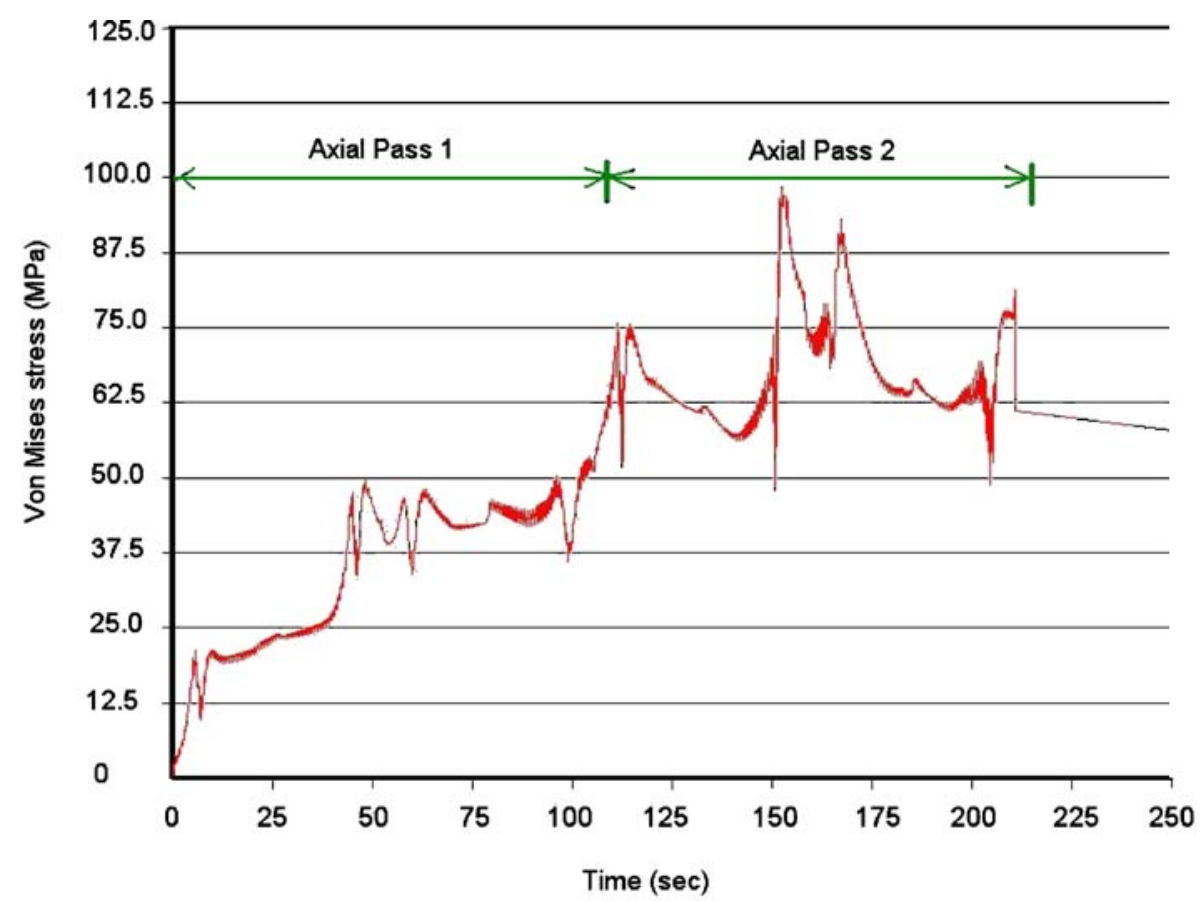

(a)

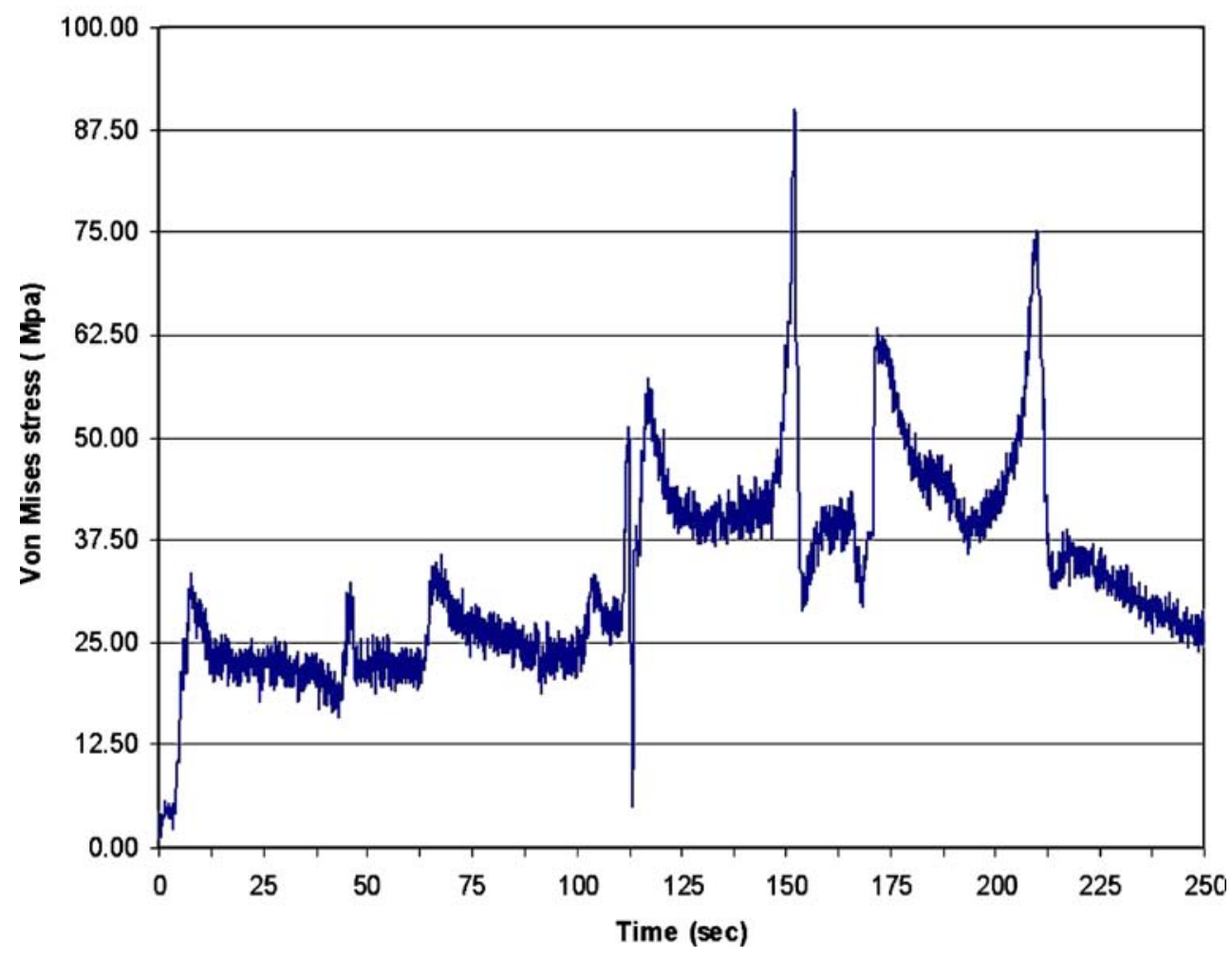

(b) loads dominate due to the presence of coolant, and thus, cyclic fluctuations were only observed. The spikes seen in the stress profiles (Figs. 16-19) show instances when the cutter was closer to the strain gauges imposing higher strain amplitudes. In all the considered test cases, it was found that the part thermomechanical deformations lie well below the elastic limit [yield strength $(Y)=503 \mathrm{MPa}$ ] of the workpiece 
Fig. 19 Predicted and measured Von Mises stress for test case 4 in Table 3. a Predicted Von Mises stress profiles for test case 4 at S1. b Measured Von Mises stress profiles for test case 4 at $\mathrm{S} 1$

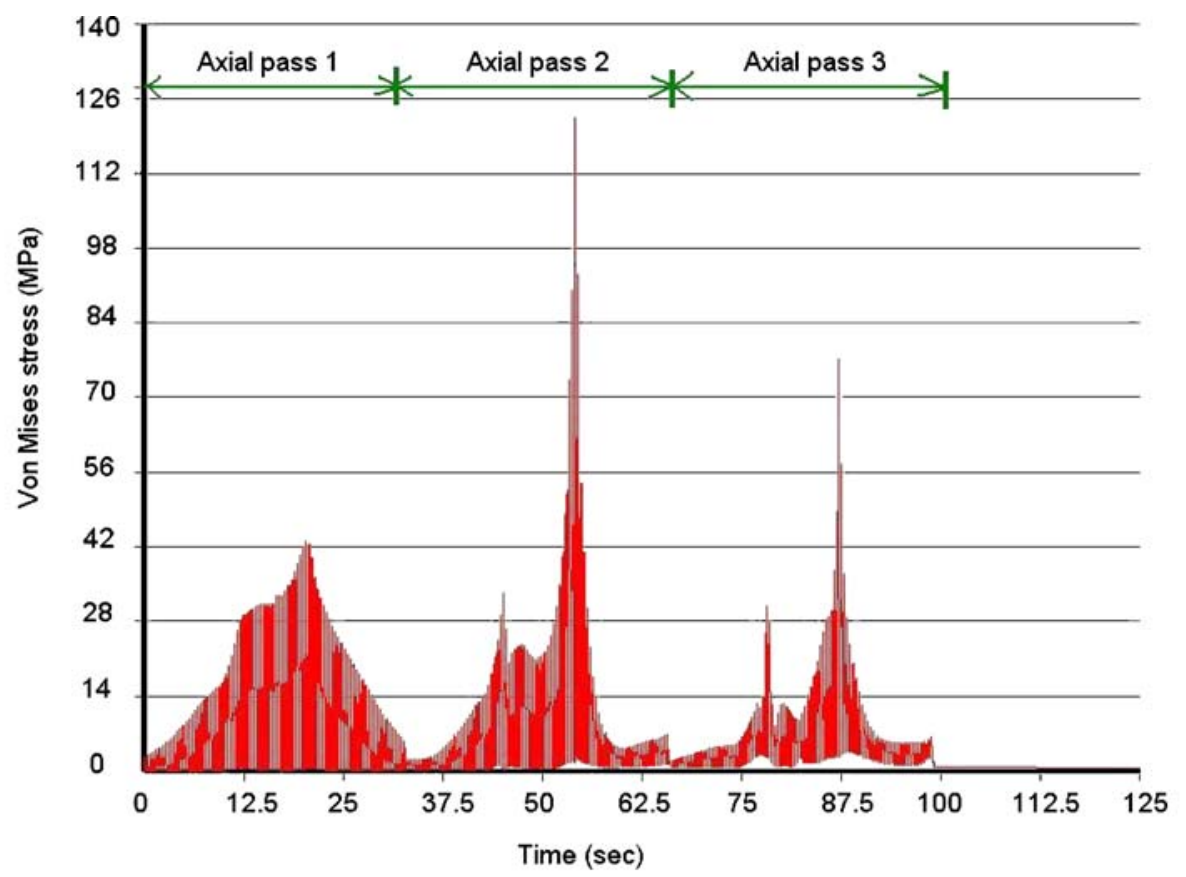

(a)

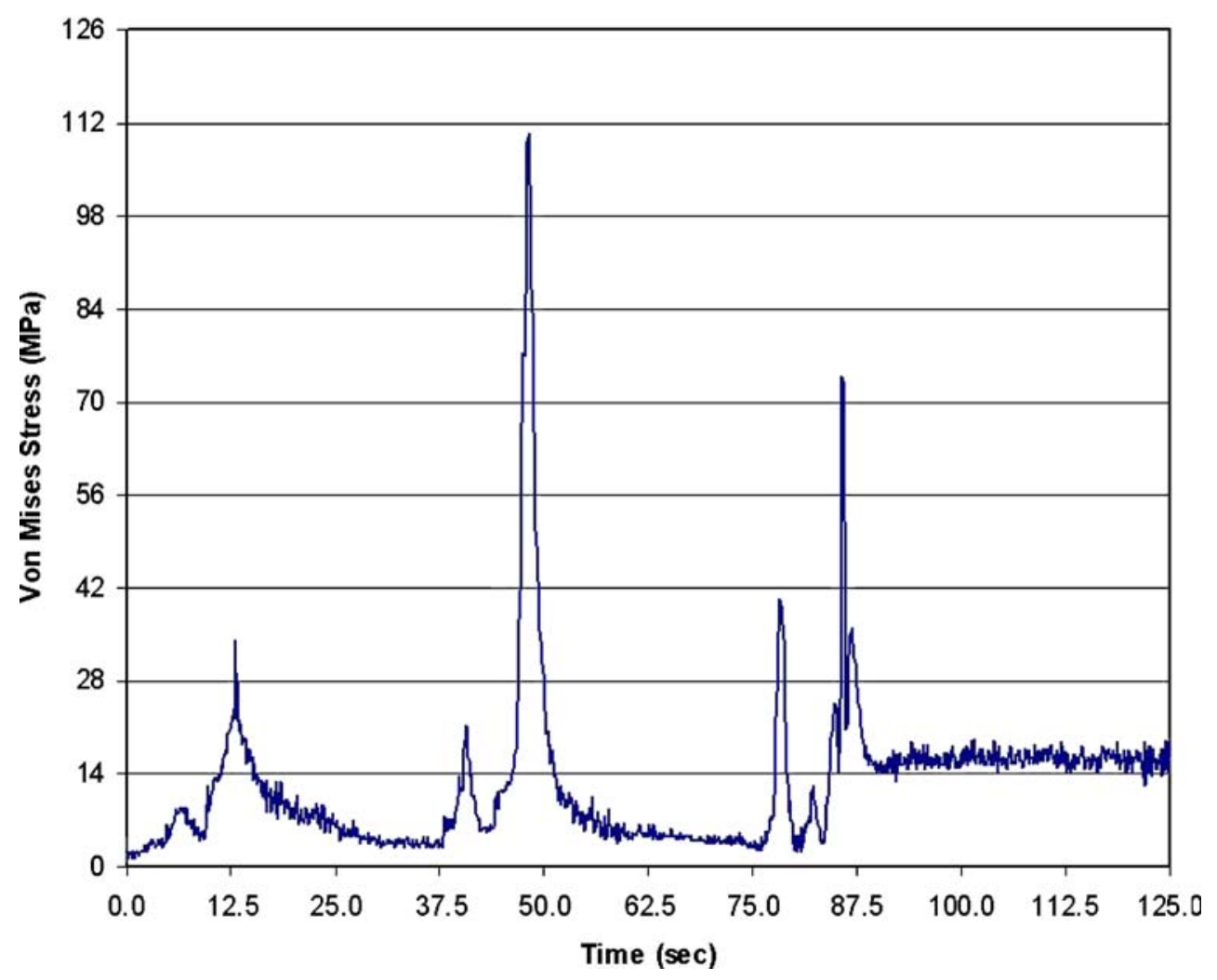

(b) material. The close resemblance between the measured and numerically predicted temperature, deflection, and stress profiles successfully demonstrated the capabilities of the developed FEM-based milling sim- ulation system for simulating the transient thermomechanical aspects of machining and assisting manufacturing engineers in designing appropriate machining strategies. 


\section{Conclusions}

In this research work, a FEM-based transient milling simulation model was developed for the prediction of workpiece transient temperature distributions, displacements, and stresses in a 3D virtual manufacturing environment by considering the effects of overall machining process parameters. The proposed system was extensively tested for a large variety of $2.5 \mathrm{D}$ prismatic parts with different degrees of geometrical complexities and various combinations of cutting parameters and fixture assemblies. It was found that the cutting parameters $\left(f_{t}\right.$ and $\left.n\right)$, workpiece thermal properties, and coolant have a major influence on the heat dissipation rate and fixturing, clamping loads, workpiecespecific cutting pressure $\left(K_{c}\right)$, and cutting parameters like feed rate and depth of cuts influence the part stability and localized deformations. The obtained transient numerical results were validated with real field data obtained during the course of this research work and will be validated further for different workpiece materials (like steel and titanium) and complex part geometries in future work. A good agreement between the numerical and experimental data shows the validity of the presented FEM-based milling simulation model in handling real-field problems. The main advantages of the presented system over previous works [7, 9, 1719] and the traditional computer-aided manufacturing) software $[2,23,24]$ are the following:

- Performs transient thermomechanical coupled field analysis of the overall machining process in a $3 \mathrm{D}$ environment.

- Provides a fast and accurate means for testing the stability of a designed fixture under transient loading conditions.

- Predicts the workpiece nonlinear behavior during machining due to its changing geometry, inelastic material properties, and fixture-workpiece flexible contacts.

- Incorporates an integrated analytical machining load model.

- Allows its efficient use in an interactive environment due to its simplicity in software design.

- Generates reports automatically, which makes the FEM results postprocessing task easier, which is always complex and very time consuming.

The developed simulation package would be an efficient means for analyzing the thermal-mechanical aspects of machining and their influence on resulting machined part quality. Thus, it allows manufacturing engineers to set appropriate machining process para- meters and obtain better machining results without needing preliminary cutting trials, which generally demands huge investment in terms of both time and money.

Acknowledgements The authors would like to convey their sincere thanks to Engr. Pietro Contini from MCM s.p.a, Italy, for providing the test cases and sharing his expertise knowledge in high-speed machining of aircraft structural parts. Also, the technical support provided by the MCM metrology department and the partial funding received from the KoBaS project (Grant no. 505339-1) to perform this work are gratefully acknowledged.

\section{References}

1. ANSYS-10.0 (2007) A FEM based commercial software, ANSYS Inc., Canonsburg, Pennsylvania(USA). http://www.ansys.com. Accessed 11 July 2007

2. CATIA V5 (2007) Computer Aided Manufacturing (CAM) software, Dassault Sytems, France. http://www.3ds.com. Accessed July 2007

3. Fang G, Zeng P (2005) Three-dimensional thermo-elasticplastic coupled FEM simulations for metal oblique cutting processes. J Mater Process Technol 168:42-48

4. Europe Union (2004-2007) Knowledge based customized services for traditional manufacturing sectors provided by a network of high tech SMEs (KoBaS). Europe Union funded project, Proposal Number: 505339-1, Call identifier: FP62002-NMP-2

5. Lazoglu I, Altintas Y (2002) Prediction of tool and chip temperature in continuous and interrupted machining. Int J Mach Tools Manuf 42:1011-1022

6. Li HZ, Zhang WB, Li XP (2001) Modeling of cutting forces in helical end milling using a predictive machining theory. Int J Mech Sci 43:1711-1730

7. Liao YG, Hu SJ (2001) An Integrated model of a Fixtureworkpiece system for surface quality prediction. Int $\mathrm{J}$ Adv Manuf Technol 17:810-818

8. Lin J (1993) Inverse estimation of the tool-work interface temperature in end milling. Int J Mach Tools Manuf 35:751760

9. Liu S, Zheng L, Zhang ZH, Wen DH (2006) Optimal fixture design in peripheral milling of thin walled workpieces. Int $\mathrm{J}$ Adv Manuf Technol 28:653-658

10. Marcio BS, Wallbank J (1999) Cutting temperature: prediction and measurement methods-a review. J Mater Process Technol 88:195-202

11. Miller MR, Mulholland G, Anderson C (2003) Experimental cutting tool temperature distributions. J Manuf Sci Eng 125:667-673

12. Ming C, Fanghong S, Haili W, Renwei Y, Zhenghong Q, Shuqiao Z (2003) Experimental research on the dynamic characteristics of the cutting temperature in the process of high-speed milling. J Mater Process Technol 138: 468-471

13. Muller B, Renz U, Hoppe S, Klocke F (2004) Radiation thermometry at a high-speed turing process. Trans ASME 126:488-495

14. Nee AYC, Whybrew K, Kumar AS (1995) Advanced fixture design for FMS. Springer, London, pp 155-173 
15. Ozel T, Zeren E (2004) Determination of work material flow stress and friction for FEA of machining using orthogonal cutting tests. J Mater Process Technol 153-154: 1019-1025

16. Potdar YK, Zehnder AT (2003) Measurements and simulations of temperature and deformation fields in transient metal cutting. J Manuf Sci Eng 125:645-655

17. Ratchev S, Liu S, Becker AA (2005) Error compensation strategy in milling flexible thin-wall parts. J Mater Process Technol 162-163:673-681

18. Ratchev S, Liu S, Huang W, Becker AA (2004) Milling error prediction and compensation in machining of low-rigidity parts. Int J Mach Tool Manuf 44:1629-1641

19. Sanchez HT, Estrems M, Faura F (2006) Analysis and compensation of positional and deformation errors using integrated fixturing analysis in flexible machining parts. Int J Adv Manuf Technol 29:239-252

20. Sandvik (2001) Sandvik tool catalogue. AB Sandvik Coromant. 2001.02, pp A197-A204

21. Shen G (1996) Modeling the effect of cutting fluids in peripheral Milling. 1996, Ph.D. Dissertation. http://wwwlib. umi.com/dissertations. Accessed 24 May 2005

22. Stephenson DA, Agapiou JS (2006) Metal cutting theory and practice, 2nd edn. Taylor and Francis, London, pp 425-450

23. UNIGRAPHICS NX (2007) Computer Aided Manufacturing(CAM) software. UGS PLM software, Plano. http://www.ugs.com. Accessed July 2007

24. VERICUT (2007) Computer Aided Manufacturing(CAM) software. CGTech, California. http://www.cgtech.com. Accessed July 2007 